\title{
Wavelet Transform for the Analysis of EEG Signals in Patients with Oral Communications Problems
}

\author{
Maria Viqueira, Begona García Zapirain, \\ Amaia Mendez Zorrilla and Ibon Ruiz \\ Deusto Institute of Technology, Deustotech-LIFE Unit, University of Deusto, Bilbao \\ Spain
}

\section{Introduction}

This study is a part of a developed project to help people who can't talk or control their movements when communication.

There are different kinds of methods to improve the communication of these people. Some examples are:

1. Methods based in the ocular movement: for example the videooculography systems, where a little camera detects the eye position and place the mouse in the same position on a monitor.

2. Physical communicators based on boards: the user points, on a board, what he wants to communicate. This method involves that the user's disability allows him to have some control over his movements.

In this case, the intention is to use a method which can be used with people whose disability do not let them utter a word (or they present a big difficult for that), neither take the whole control of their movements.

This kind of disability may be due to several cerebral palsy, one example of that could be athetosis. This disease is a kind of paralysis which also presents injuries in the extrapyramidal system, which is part of the nervous system. This illness causes that the one who suffers it cannot take the whole control of his movements, and the difficulties at the time to talk (in some cases it prevent them the speech totally).

For these end, we have chosen to work with the signals from an EEG, which is a brain activity record. When analyzing the signals, the intention is to detect what a person wants to say. Therefore it wouldn't be necessary that the user had a hole control of the movements (or even eyes), because what is pretended is to interpret what the user wants to say, without having to express it externally. Nowadays EEG is a very used method applied to improve user interaction (see the literature [1-2]).

The brain shows electrical activities on different frequency bands and it can be useful analyze each frequency band separately. 
Fourier transform is a very used method in frequency domain, but it presents the inconvenient that it does not show temporal information of the signal. It means that Fourier shows the signal frequency ranges, but it doesn't inform when we are in a frequency or in another.

Wavelet transform, explained widely in [1], is a method to analyze the signal in timefrequency scale. This method is very useful in non stationary signals analysis, it means: those signals which don't stay constant over time.

The use of the different frequency bands allows to separate the signal in different frequency components in order to eliminate noise signals and information which doesn't provide anything significant.

In this case we want to analyze the EEG signal in different frequency bands to get the P300, which is a signal that appears as an answer to a light or sound stimulus.

The P300 wave is between the band frequencies corresponding to [0-8Hz]. The predominant component of the $\mathrm{P} 300$ is about $2.5 \mathrm{~Hz}$, existing also another theta component $(6 \mathrm{~Hz}$ approximately), which appears in a latter zone [4]. Analyzing this band, we can detect the presence or absence of the P300.

The method which has been used to help in the communication consists in illuminate different letter, so that, when the letter that the user is watching is illuminated (target letter), the brain sends the P300 wave as an answer to that stimulus.

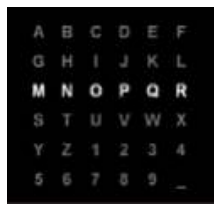

Fig. 1. Matrix shown on the screen of Competition BCI

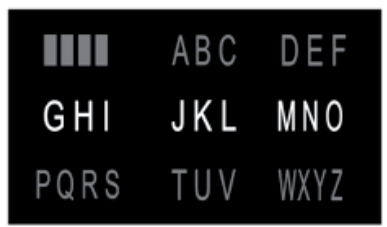

Fig. 2. Matrix shown on the screen of the final application of this project

If it illuminates the target row, it results the $\mathrm{P} 300 \mathrm{~b}$, whereas if the illuminated row is not the one the user is watching, appears the P300a.

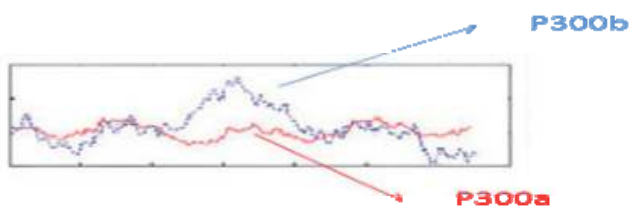

Fig. 3. P300a and P300b 
Detecting the signal, which appears between 300 and 600 milliseconds after the target photostimulate, and knowing the sequence of letter illumination, we can predict the letter that the user wants to say.

We have decided working with the Discrete Wavelet Transform (DWT) because it doesn't require so much memory as the Continuous Wavelet Transform (CWT), it is efficient if we use scales in powers of 2, it presents higher facilities to analyze numerically the transformed data and the calculations are faster.

This technique has been used in studies in order to get the P300, such as [21]and [22], and combining the DWT with another techniques [26] and [27].

The DWT performs basically two functions:

1. It filters the signal along a low-pass filter and another high-pass filter to obtain the approximate and detail signal coefficients in different ranges of frequency.

2. Sub-sampling of the output signals.

The successive decompositions are made from the signal obtained in the low pass filter.

When developing the algorithm, we have made a preliminary study to understand the behavior of the P300 and Wavelet Transform.

From this study, conclusions are reached concerning the shift of the signal according to the mother wavelet chosen and the frequency band where the P300 is best detected.

Subsequently, there has performed a second part to detect which wavelet is more appropriated to integrate at the final application and in which channels we have obtained higher success percentage, because the EEG to use has only 4 channels.

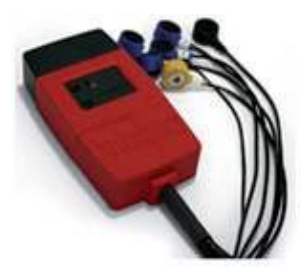

Fig. 4. EEG 4 channels

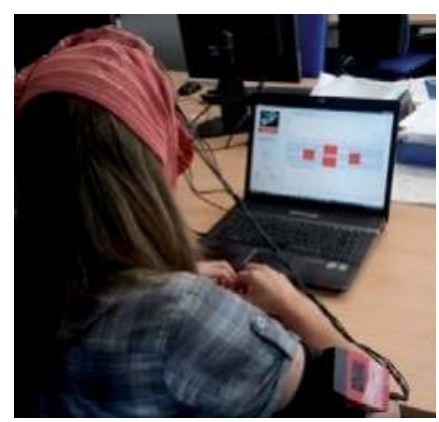

Fig. 5. Final application 


\section{State of the art}

\subsection{Technical}

The Wavelet Transform results very useful in the analysis of non stationary signals [30-31], where the signal of the study presents parts with different frequencies over time.

Wavelet is not only useful in the study of signs, but it is also frequently used in digital image processing, although this study focuses on the first case.

In medicine applications, it is used in a case which is needed to detect any peculiarity in the registry of biomedical signals.

1. Noise removal: the Wavelet decomposition is produced without spaces and without overlap the data, so the decomposition process is totally reversible (the signal can be rebuilt). Thus, they result useful in the algorithms where it is wished to retrieve the original information with a minimal loss. Wavelet Transform is also used for removing the noise in images, such as the noise removal of planar images in nuclear medicine [5][32-34].

2. Feature extractions: as it has been said before, the DWT is used in non stationary analysis. It allows the detection of the "oddballs" that can be originated in EEG, EOG or ECG signals, among others[6][35].

3. Detection of tumors [23]: extracting texture features through the DWT, it can help in the diagnosis of certain tumors, as the breast [24].

4. Seizures:

a. Epilepsy: it is possible to detect certain epilepsy cases using the DWT. There are studies where it has been used the Wavelet Transform to detect the seizures in newborn, like in [7] and [8]. Knowing in which moment the seizures are happening, it can help in the diagnosis of diseases [28].

5. Electrocardiograms: the use of the DWT allows to analyze the ECG signals and make a classification of them [9]. Similarly, it allows to detect if there exits an ECG abnormality [10].

6. Pregnancy: we can know if the fetus presents any problem during the pregnancy, working with the images obtained by ultrasounds [11].

7. P300 detection: Wavelet transform has been used in previous studies to detect the P300 in EEG signals, like in [12], [13] and [14].

8. Detecting the frame of mind: there are differences between thinking a movement and keeping the mind relaxed. The use of the wavelets indicates the behavior of the brain in the different bands, so it can determinate if an individual is thinking in something or not, coming to know which movement is been imagined.

9. Alzheimer: as study of this disease, there are methods which start from wavelet coefficient to test the difference between a healthy people EEG and EEG from Alzheimer patients [25].

\subsection{Social}

The analysis methods in the frequency domain are useful to detect possible anomalies, which is a great help in medicine applications. Wavelet is a method which represents signals in time and frequency scales, but there are methods which work in time-frequency distribution and they are also used in medical applications. 
A new method which has acquired relevance in the signal analysis is the Matching Pursuit, which consists in select, in a signal dictionary, the signal which matches better with the one of the study.

Usually, the methods used in time-frequency distributions use classify algorithms to separate different kinds of signals [15].

\section{Methods}

\subsection{Wavelet Transform}

The Wavelet Transform is defined by:

$$
W_{f}(s, \tau)=\int f(t) \Psi_{(s, \tau)}^{*}(t) d t
$$

The wavelets are generated from a wavelet function $\psi(\mathrm{t})$, called "mother wavelet", which is defined as:

$$
\Psi_{\mathrm{s}, \mathrm{\tau}}(\mathrm{t})=\frac{1}{\sqrt{\mathrm{s}}} \Psi\left(\frac{\mathrm{t}-\mathrm{\tau}}{\mathrm{s}}\right)
$$

being $\tau$ the translation factor and " $\mathrm{s}$ ", the dilation factor.

The signal $f(t)$ is sampled by mother wavelet versions, which are dilated and moved.

The DWT is defined by the following way:

$$
W(j, k)=\sum_{j} \sum_{k} f(x) 2^{\frac{-j}{2}} \Psi\left(2^{-j} x-k\right)
$$

\section{$3.2 \mathrm{BCl} 2003$ database}

We have used the database corresponding to the BCI competition. The data have been obtained with a sample frequency of $240 \mathrm{~Hz}$. They produced 12 illuminations (one for each row and column) and, for each letter to predict, they do 15 repetitions (each one is illuminated 15 times). Each illumination lasts 100 milliseconds and, between each illumination, there is a space of 75 milliseconds.

This database has been used in more occasions to make studies with EEG signals and detect the P300, like in [16] or [29].

There have been performed three sessions, with different trials, where the first two are destined as a part of the training, where they difference the illumination of a target or non target row or column. The third session corresponds to the words to predict.

The algorithms developed have been used initially with this database for test its efficacy. This database provides the result of 64 channels of study and it has applied the algorithm to all of them in order to know the behavior of the P300 in each one, and testing in which ones the P300 is best appreciated. 
The Wavelet Transform performs a set of consecutive filters, leading to decomposition of the signal in different levels and frequency bands. In this case, the level decomposition results:

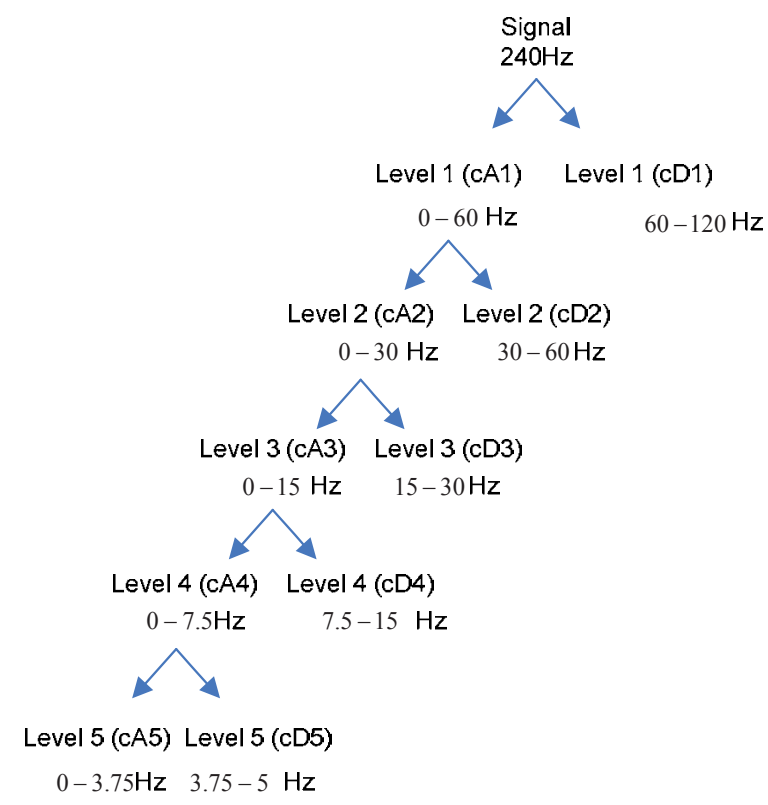

Fig. 6. Decomposition level

The result of the last low-pass filter corresponds to the approximate coefficients, where we should detect the P300 main component.

Initially, we have separated the target and the non target samples corresponding to the different trials of the season 1 .

To check the algorithm efficacy, we have probed with the trials corresponding to the third session, which is the session of prediction.

\subsection{Matlab Toolbox and mother wavelet}

The algorithm has been developed entirely in Matlab and, for Wavelet Transform operations, we have used the Wavelet Toolbox from Matlab.

Moreover, the wavelets used have been the ones which this toolbox gives. The choice of one mother wavelet or another conditions the form of the low-pass and high-pass filters, so the Wavelet Transform will be different depending on the mother wavelet chosen.

The chosen mother wavelets have been the following ones: bior3.9, bior3.7, bior3.5, bior3.3, rbio1.5, rbio1.3 and DB9, as in [21], because of the similarity with the P300, [17] and [18]. 
It has been studied the behavior of the signal by the following way:

\begin{tabular}{|c|c|c|}
\cline { 2 - 3 } \multicolumn{1}{c|}{} & $\begin{array}{c}\text { Approximate } \\
\text { coefficients }\end{array}$ & $\begin{array}{c}\text { Detail } \\
\text { coefficients }\end{array}$ \\
\hline $\begin{array}{c}\text { Frequency band } \\
\text { level 4 }\end{array}$ & $0-7,5 \mathrm{~Hz}$ & $7,5-15 \mathrm{~Hz}$ \\
\hline $\begin{array}{c}\text { Frequency band } \\
\text { level 5 }\end{array}$ & $0-3,75 \mathrm{~Hz}$ & $3,75-7,5 \mathrm{~Hz}$ \\
\hline
\end{tabular}

Table 1. Frequency ranges

\section{System design}

Below it is detailed the design of the algorithm that we pretend integrate into the final application.

In the section called "High level designs" it is shown a general scheme of the data acquisition and its treatment, and one scheme with de different modules and jobs which compose the study.

In the section called "Low level design" it will be concreted the reflected jobs in the previous section.

\subsection{High level design}

The main application makes the following operations:

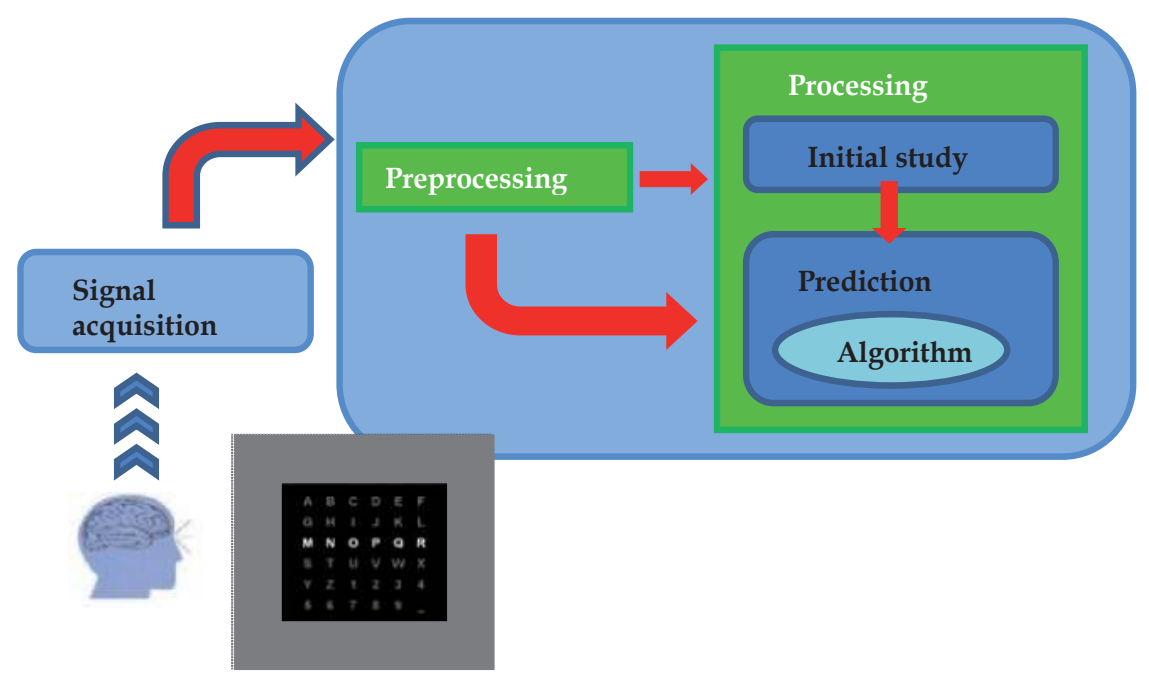

Fig. 7. Application scheme 
To develop the algorithm, we make a first study and, then, we develop the method based in the conclusions obtained in the first part of the study.
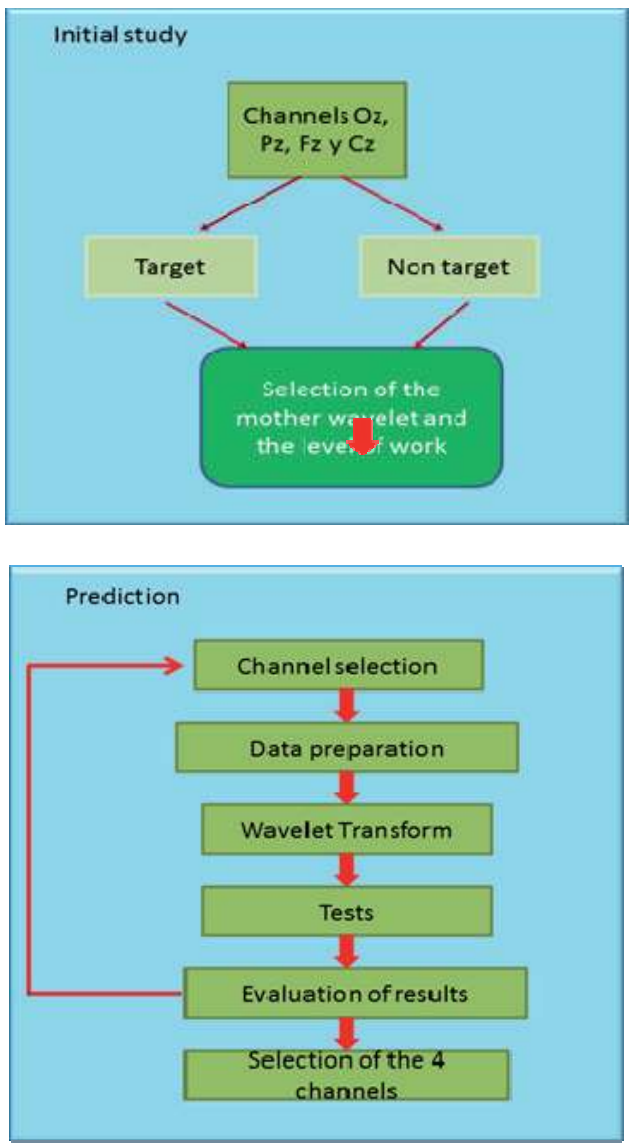

Fig. 8. General scheme

In the initial study it can be observed the behavior of the target and non target signals to check the shift that each wavelet produces to the signal. Subsequently, we work between the corresponding time interval to localize the P300 depending on the used mother wavelet.

\subsection{Low level design}

\section{Initial study}

The initial study provides information about the behavior of the P300 at the frequency domain. Studying the difference between target and non-target data, it is possible to obtain some initial conclusions about this behavior. 


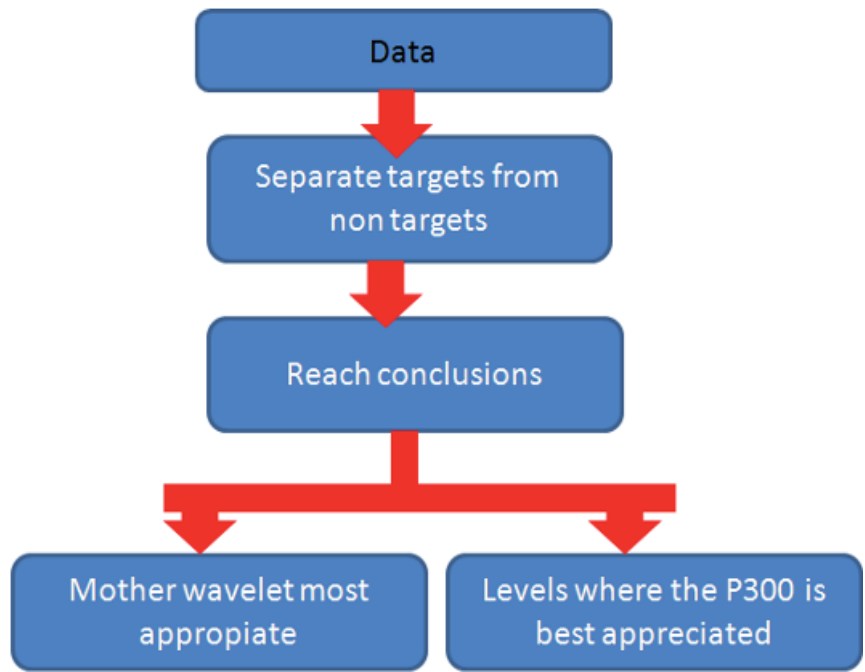

Fig. 9. Objectives of the initial study

It involves the following steps:

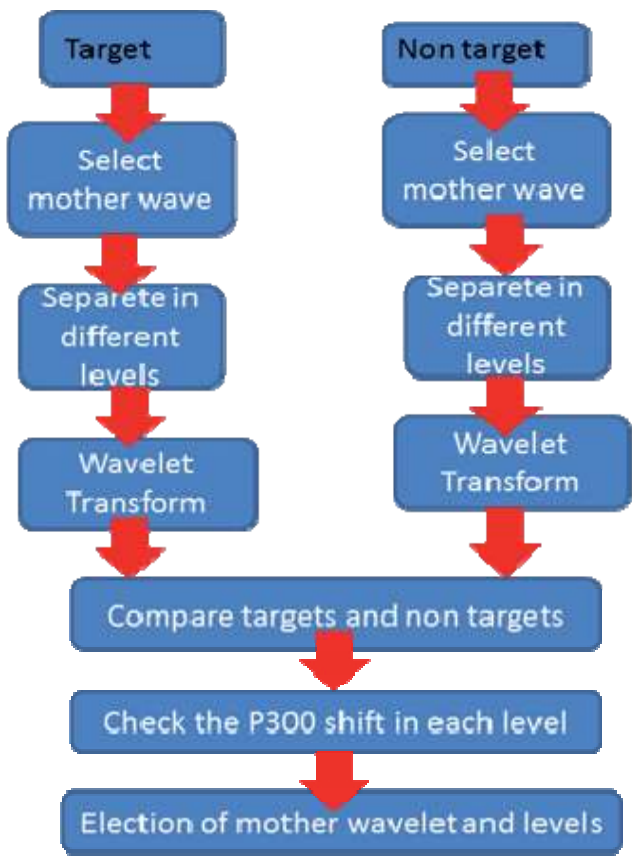

Fig. 10. Initial study 
On the one side, separate the targets and non target data corresponding to Albany BCI competition. With these data, it performs the Wavelet Transform at the levels where the P300 should be appreciated to check the time intervals where the peak is appreciated.

As it has been said before, the interval where the peak is best appreciated is between 0 and $7,5 \mathrm{~Hz}$.

After doing this initial study it can be observed that there exists a big difference between the signals corresponding to the targets and the ones which are not target. This difference is well appreciated because the separation of the data has been performed by averaging the results of several sessions: the more signals are averaged; the greater will be difference between targets and non targets.

The prediction stage won't show that difference so clearly, but with the initial study it can be known where will be best appreciated.

As it has been said before, the interval where the peak is best appreciated is between 0 and $7,5 \mathrm{~Hz}$.

After doing this initial study it can be observed that there exists a big difference between the signals corresponding to the targets and the ones which are not target. This difference is well appreciated because the separation of the data has been performed by averaging the results of several sessions: the more signals are averaged; the greater will be difference between targets and non targets.

The prediction stage won't show that difference so clearly, but with the initial study it can be known where will be best appreciated.

\section{Preparing data}

This stage is done in the initial study and on the prediction of the words.

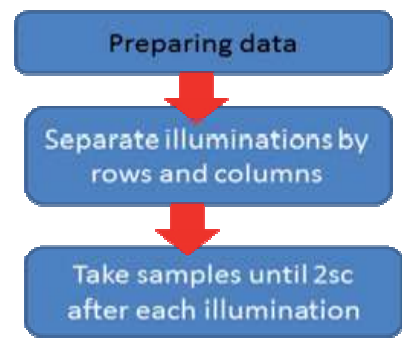

Fig. 11. Preparing data

Data are separated according to the row or column illuminated, obtaining in that way, 12 different data sets. It takes samples from the illumination until 2 seconds after in order to obtain the number of data which ensures the correct transformation at the last level (in this case, level 5). Using the Matlab command wmaxlev, it can check that the number of samples is correct.

The reason of separate columns and rows is because the cross of the target row and the target column will be the letter that the user is looking. 


\section{Wavelet Transform}

The Wavelet Transform has been also used in the initial study and at the time of predicting the words. After the transformation, the data will be at the frequency domain.

The part which transforms the data makes the following steps:

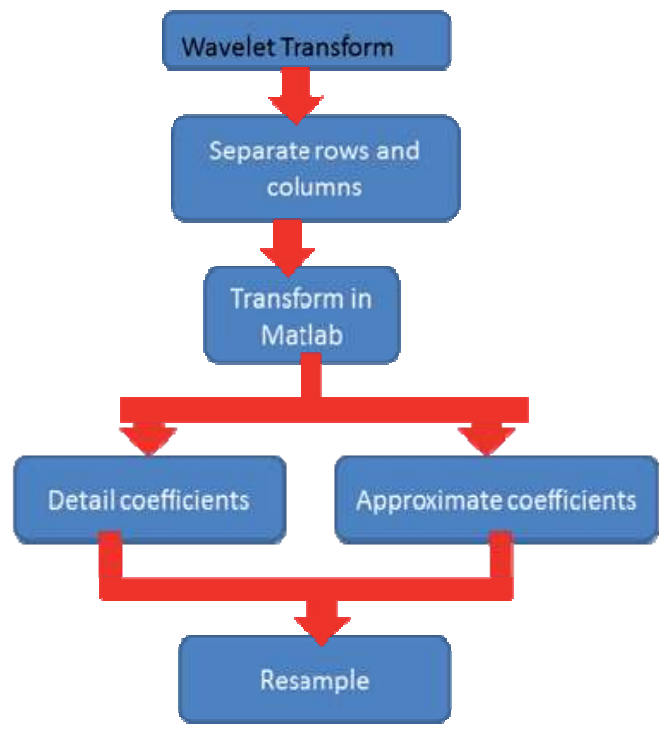

Fig. 12. Wavelet Transform

The transform of each row and column is made in Matlab (12 transformations in total for each letter, corresponding at 6 columns and 6 rows) to give rise to the different frequency bands. The detail coefficients are the high-pass filter result, whereas approximate ones are obtained from the low-pass filter. In this case:

Level $4 \rightarrow[3.75-7.5 \mathrm{~Hz}]$ (Aprox 4) and [7.5-15Hz] (Det 4)

Level $5 \rightarrow[0-3.75 \mathrm{~Hz}]$ (Aprox 5) and [3.75-7.5] (Det 5)

Finally, it is made a resample stage to add more samples.

\section{Transform in Matlab}

The first thing that is needed is to ensure that the Wavelet Transform will be correct with the number of samples which have been selected. To assure this, we use the command wmaxlev() in Matlab. With this command it is possible to know the highest level of work with guarantees by giving the number of samples and the mother wavelet.

In this case, taking two seconds after the illumination is enough to ensure the correct transform at level 5 .

The Wavelet Transform has been performed for each one of the 64 channels. In the final application, there will be only four channels, so the transform will be much faster. 


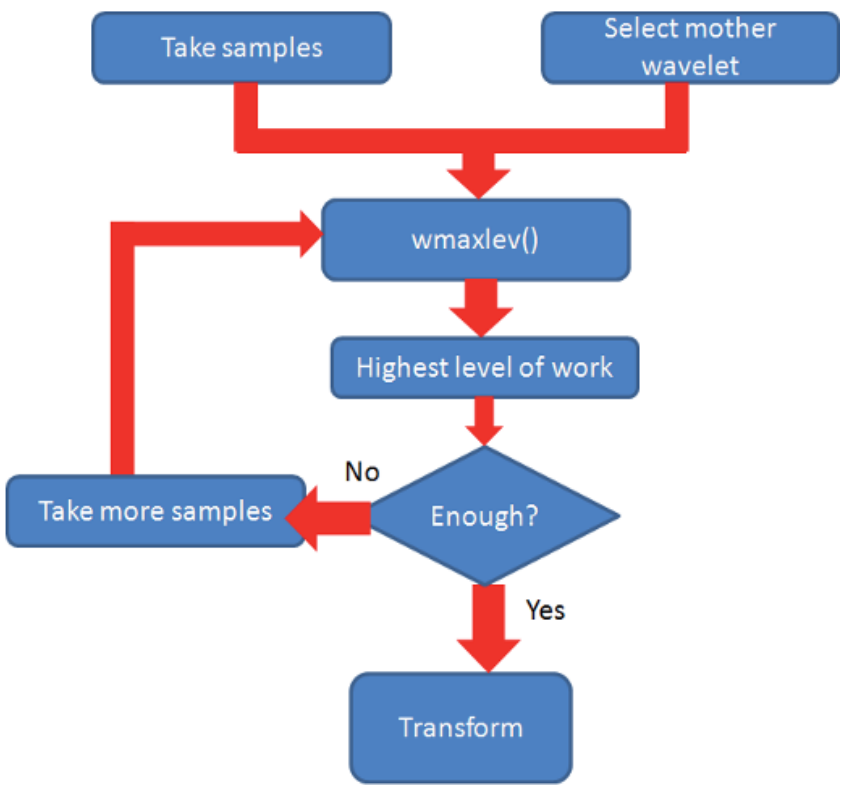

Fig. 13. Transform in Matlab

The following scheme shows the instructions used in Matlab:

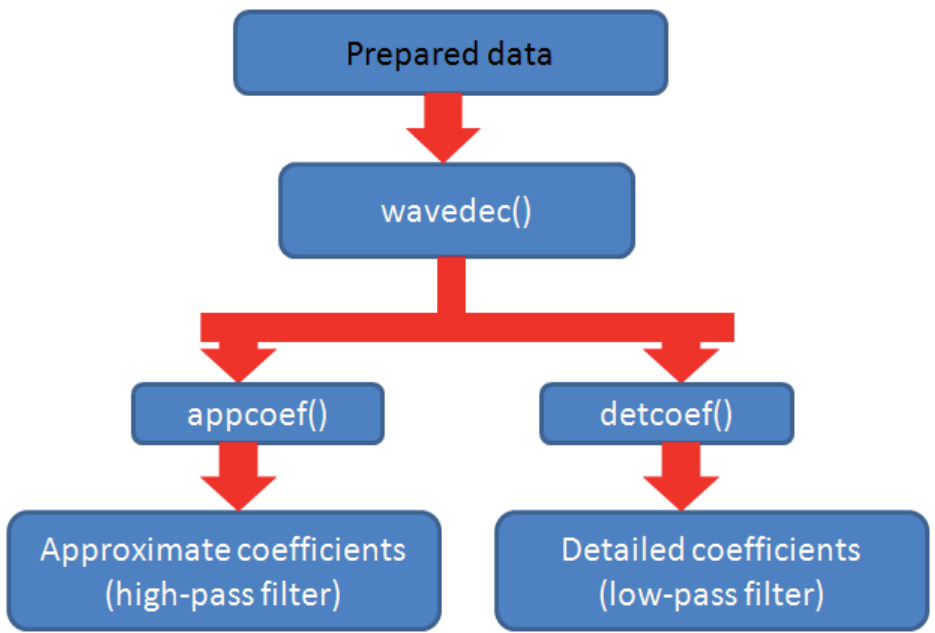

Fig. 14. Instructions in Matlab

To obtain the Wavelet Transform it is needed to give the signal to transform, the mother wavelet that will be used as filter, and the level of work. 
In this case, as we need ranges of frequencies at level 4 and level 5, we have to do the transform twice (one for each level).

\section{Test}

To detect the letter where the P300 has been appreciated, it performs the following operations:

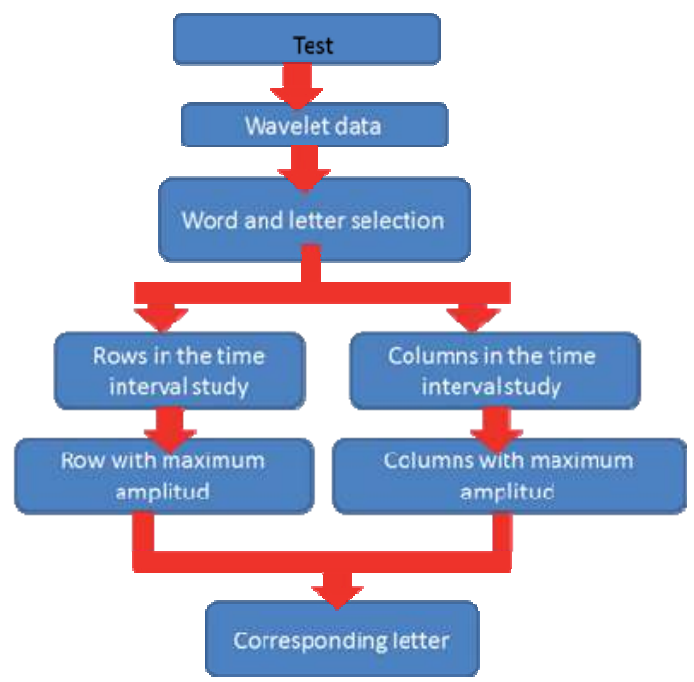

Fig. 15. Test

Once the transform is made, it takes the samples corresponding to the interval obtained in the study stage. On one side, it compares the 6 columns and, by the other side, the 6 rows; thus, it takes as target row and column the ones which present a higher peak than the rest.

Finally, it localizes the letter corresponding to these row and column.

After obtaining the letter, there is also another program which compares the theoretical letter with the real obtained and shows the average of success for each channel.

\section{Results}

\section{Initial study}

For this first part, we have used the following channels: FZ, CZ, PZ and OZ. We wanted to know the shift that means, for the P300, the election of one mother wavelet or another. The same way, we wanted to know in which levels is best appreciate the difference between a target and non target.

Mother wavelets: bior3.9, bior3.7, bior3.5, bior3.3, rbio1.5, rbio1.3 and DB9.

After the corresponding transformation, we observe a higher peak in the following time interval: 
CZ channel:

\begin{tabular}{|l|l|l|l|l|}
\hline Wavelet & Aprox 4 & Det 4 & Aprox 5 & Det 5 \\
\hline bior3.9 & {$[0.5-0.6]$} & {$[0.5-0.6]$} & {$[0.6-0.7]$} & \\
\hline bior3.7 & {$[0.4-0.6]$} & & {$[0.5-0.7]$} & \\
\hline bior3.5 & {$[0.4-0.6]$} & {$[1-1.2]$} & {$[0.4-0.7]$} & - \\
\hline bior3.3 & {$[0.3-0.5]$} & {$[0.5-0.7]$} & {$[0.4-0.6]$} & - \\
\hline rbio1.5 & {$[0.4-0.55]$} & & {$[0.4-0.6]$} & - \\
\hline rbio1.3 & {$[0.3-0.5]$} & {$[0.4-0.5]$} & {$[0.3-0.5]$} & \\
\hline db9 & {$[0.75-0.9]$} & & {$[0.9-1.2]$} & \\
\hline
\end{tabular}

Table 2. Time intervals for $\mathrm{CZ}$ channel

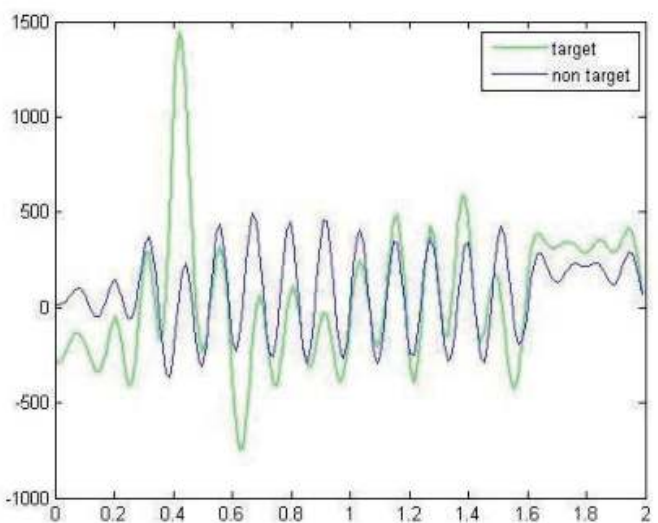

Fig. 16. bior3.7, level 4

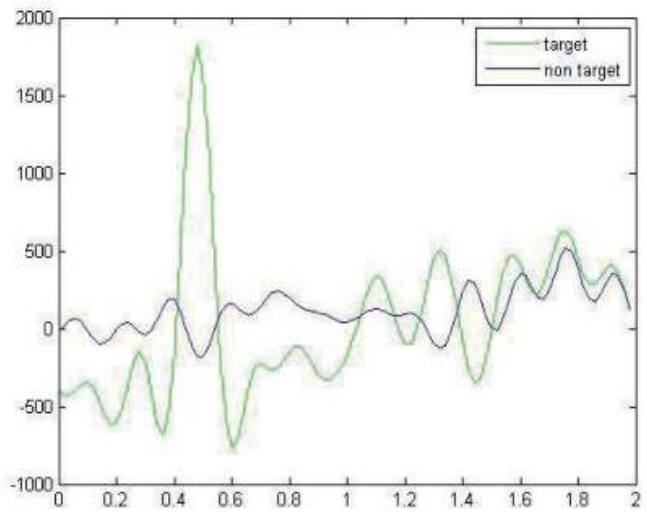

Fig. 17. bior3.5, level 5 
PZ channel:

\begin{tabular}{|c|c|c|c|c|}
\hline Wa velet & Aprox 4 & Det 4 & Aprox 5 & Det 5 \\
\hline bior3.9 & $=$ & - & {$[0.6-0.75]$} & \\
\hline bior 3.7 & $=$ & {$[0.4-0.6]$} & {$[0.5-0.7]$} & \\
\hline bior 3.5 & $=$ & & {$[0.45-0.65]$} & \\
\hline bior 3.3 & - & $=$ & {$[0.35-0.6]$} & \\
\hline rbio1.5 & {$[0.4-0.55]$} & - & {$[0.4-0.6]$} & \\
\hline rbio 1.3 & {$[0.34-0.5]$} & - & {$[0.3-0.55]$} & \\
\hline$d b 9$ & & & {$[0.9-1.1]$} & \\
\hline
\end{tabular}

Table 3. Time intervals for PZ channel

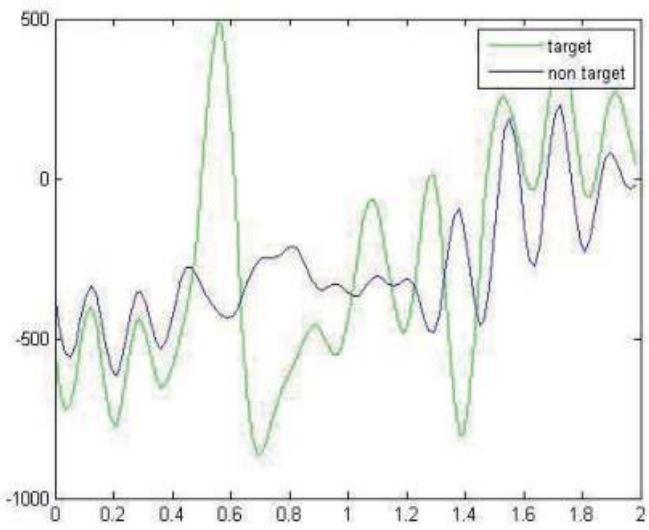

Fig. 18. bior3.7 level 5

FZ channel:

\begin{tabular}{|l|l|l|l|l|}
\hline Wavelet & Aprox 4 & Det 4 & Aprox 5 & Det 5 \\
\hline bior3.9 & {$[0.5-0.6]$} & {$[0.5-0.6]$} & {$[0.6-0.7]$} & - \\
\hline bior3.7 & & {$[0.4-0.6]$} & {$[0.45-0.65]$} & \\
\hline bior3.5 & {$[0.4-0.6]$} & {$[1-1.2]$} & {$[0.45-0.66]$} & \\
\hline bior3.3 & {$[0.4-0.6]$} & & {$[0.4-0.6]$} & \\
\hline rbio1.5 & {$[0.35-0.5]$} & {$[0.6-0.7]$} & {$[0.4-0.6]$} & - \\
\hline rbio1.3 & {$[0.3-0.45]$} & & {$[0.3-0.5]$} & \\
\hline db9 & {$[0.75-0.9]$} & & $0.9-1.5]$ & - \\
\hline
\end{tabular}

Table 4. Time intervals for FZ channel 


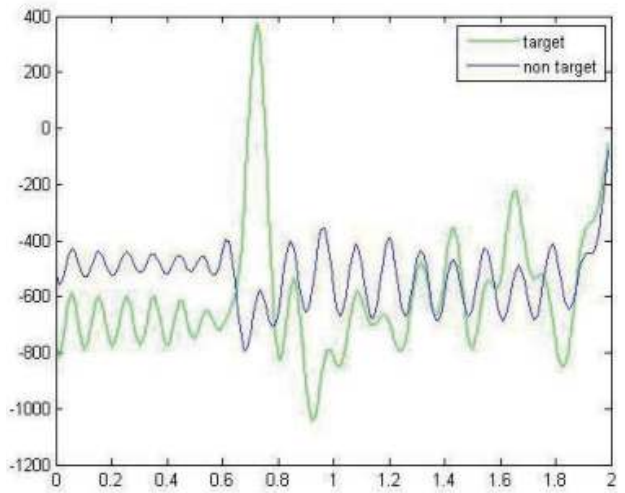

Fig. 19. DB9, level 4

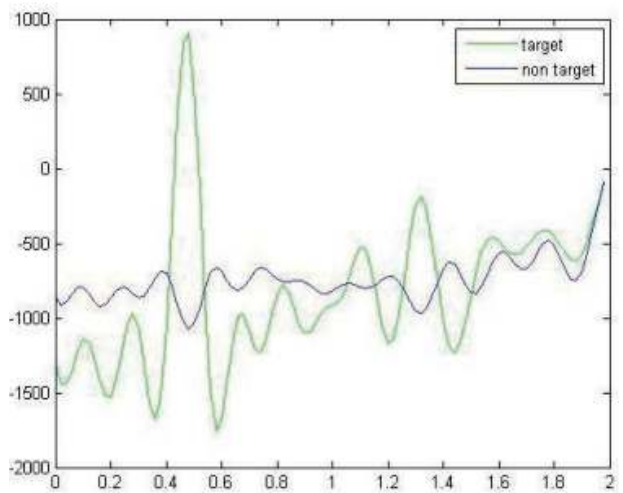

Fig. 20. bior3.5, level 5

The cells with green background show the frequency band where it is appreciated a higher peak. In case of FZ channel, the yellow background makes reference to time interval that, without been where the peak is the highest, show a considerable difference.

From OZ cannel we have not obtained significant differences, so the results are not shown.

\section{Second stage}

The Project where this part is integrated, consist in detect the P300 using an EEG with only 4 channels. For that, it is only shown the results of the 4 channels where the percentage of success has been higher.

It also shows the relative absolute error, the equations is the following:

$\mathrm{AE}=\mathrm{TV}-\mathrm{RV}$

TV $\rightarrow$ Theoretical value (100)

$\mathrm{RV} \rightarrow$ Real value 
The hit rate is applied by letter, no by the whole word.

rbio1.5

\begin{tabular}{|l|l|l|l|l|}
\hline Word & FCl & FCZ & CZ & FZ \\
\hline FOOD & BCCC- & BCCC- & BCCB- & BCFA- \\
\hline MOOT & MQOT- & MQOT- & MOOW- & MQOW- \\
\hline HAM & BAM- & BAM- & BAM- & BAM- \\
\hline PIE & PIE- & PIE- & PIE- & PIE- \\
\hline CAKE & CAKE- & CAKE- & CFKE- & CAKE- \\
\hline TUNA & TUNA- & TUNA- & SUNA- & TUBA- \\
\hline Z YGOT & Z5GOX & 45GOX & Z5GOX & 4YGOX \\
\hline 4567 & $4567-$ & $4567-$ & $4567-$ & $4567-$ \\
\hline Success & $\mathbf{7 4 . 2} \%$ & $\mathbf{7 1 . 9 7} \%$ & $\mathbf{6 7 . 7 5} \%$ & $\mathbf{6 7 . 7 4} \%$ \\
\hline
\end{tabular}

Table 5. Predicted letters for rbio1.5

Average of the 4 channels: $70.415 \%$

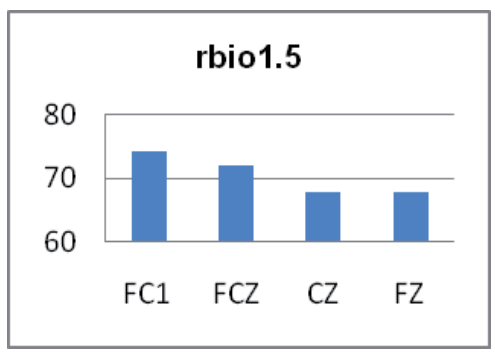

Fig. 21. Channel comparison for rbio1.5

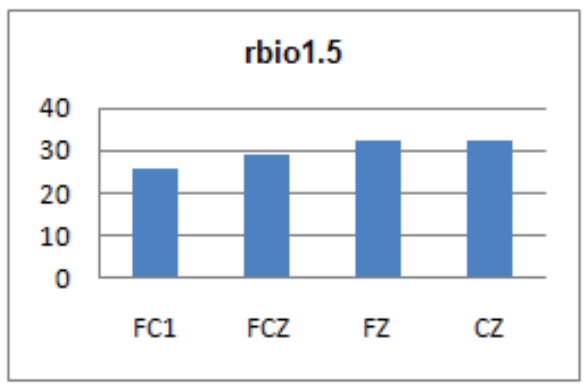

Fig. 22. Errors rbio1.5

None of the four channels have an error less than the $20 \%$, so, although the success rate could be accepted around 65 . 


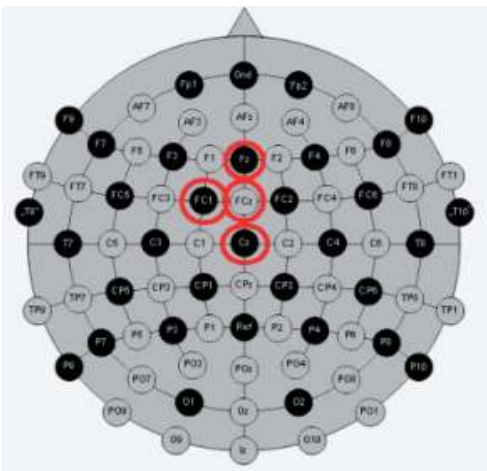

Fig. 23. Electrodes localization for rbio1.5

The obtained peaks have the following forms:

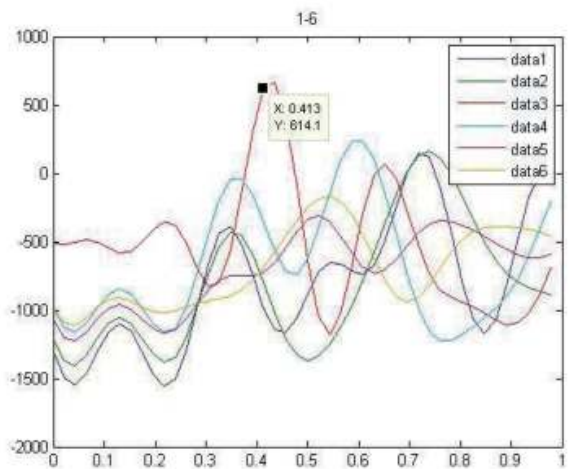

Fig. 24. Letter C, columns, FC1

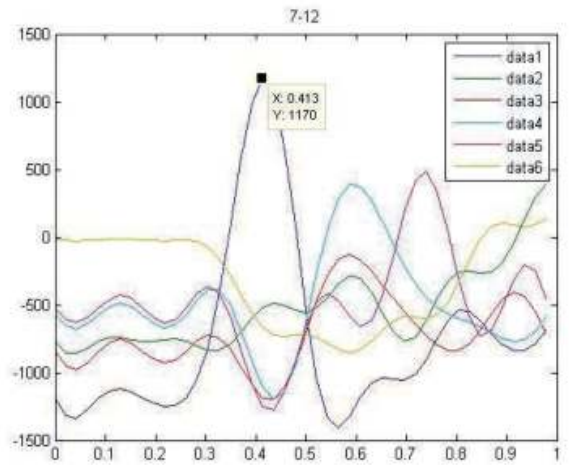

Fig. 25. Letter C, rows, FC1 
rbio1.3

\begin{tabular}{|l|l|l|l|l|}
\hline Word & FCl & FCZ & FZ & F2 \\
\hline FOOD & FCCC- & ECCC- & ECCC- & ECCC- \\
\hline MOOT & GQOT- & MQOT- & GQOT- & GQOT- \\
\hline HAM & BAM- & BAM- & BAM- & BAM- \\
\hline PIE & PIE- & PIE- & PIE- & PIE-- \\
\hline CAKE & CAKE- & CAKE- & CAKE- & CAKE- \\
\hline TUNA & TOBA- & TCBA- & TCBA- & TCBA- \\
\hline ZY GOT & 4YGOX & 4YGOX & 4YGCX & 4YGIX \\
\hline 4567 & $4567-$ & $4567-$ & $4567-$ & $4567-$ \\
\hline Success & $67.74 \%$ & $67.74 \%$ & $61.3 \%$ & $61.3 \%$ \\
\hline
\end{tabular}

Table 6. Predicted letters for rbio1.3

Average of the 4 channels: $64.52 \%$

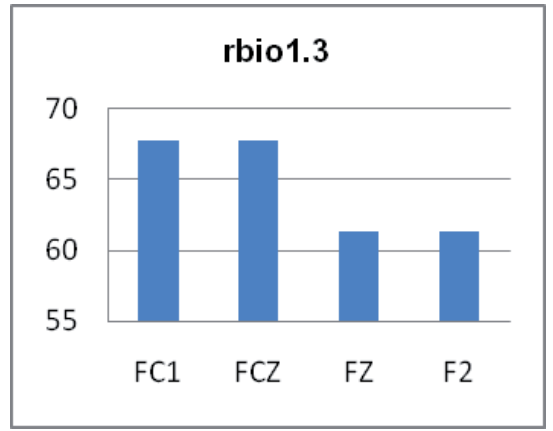

Fig. 26. Channel comparison for rbio1.3

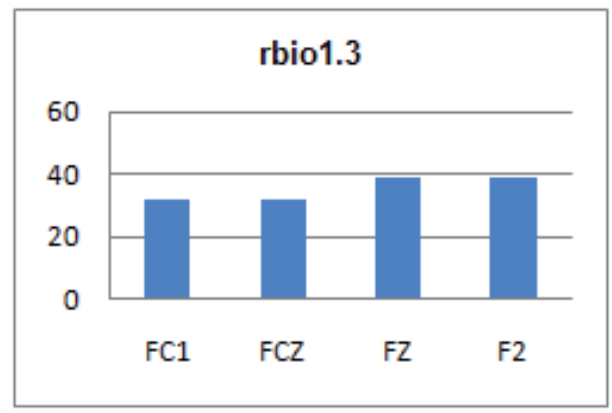

Fig. 27. Errors rbio1.3

The success rate is worse than the previous wavelet. In this case, the rbio family doesn't arrive at the $80 \%$ of success. 


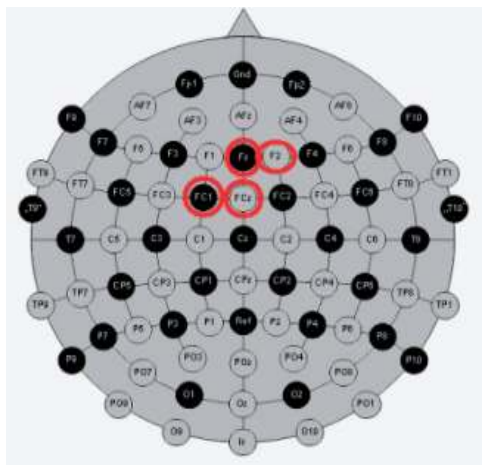

Fig. 28. Electrodes localization for rbio1.3

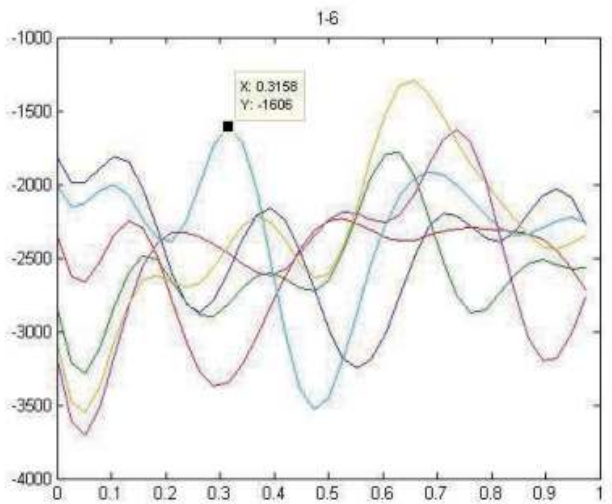

Fig. 29. Letter $\mathrm{P}$, columns, FC1

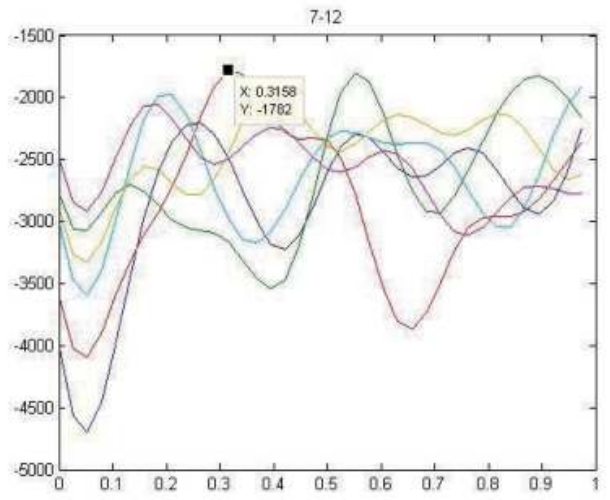

Fig. 30. Letter P, rows, FC1 
bior3.5

\begin{tabular}{|l|l|l|l|l|}
\hline Word & FCZ & FCl & Fl & FZ \\
\hline FOOD & FCCC & FCCC- & FCCC- & FCCC- \\
\hline MOOT & MOOT- & MOOT- & MQOT- & MQOT- \\
\hline HAM & BAM- & BAM- & BAM- & BAM- \\
\hline PIE & PIE- & PIE- & FIE- & PIE- \\
\hline CAKE & CAKE- & CAKE- & CAKE- & CAKE- \\
\hline TUNA & TCNA- & TONA- & TCNA- & TCNA- \\
\hline ZY COT & ZSGON & ZSAON & ZYGCX & ZYGCX \\
\hline 4567 & $4567-$ & $4 Y 67-$ & $4557-$ & XY67- \\
\hline Success & $\mathbf{7 7 . 4 2} \%$ & $\mathbf{7 0 9 7} \%$ & $\mathbf{7 0 9 7} \%$ & $\mathbf{7 0 9 7} \%$ \\
\hline
\end{tabular}

Table 7. Predicted letters for bior3.5

Average of the 4 channels: $72.58 \%$

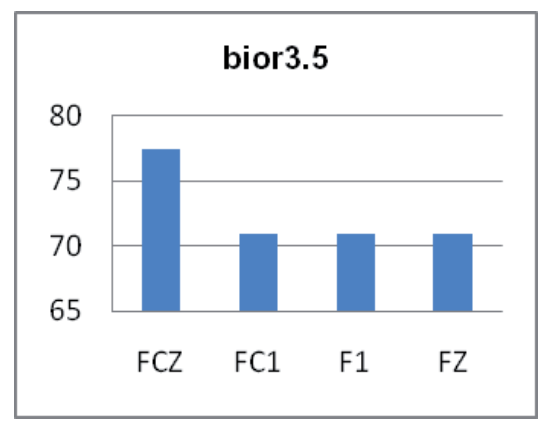

Fig. 31. Channel comparison for bior3.5

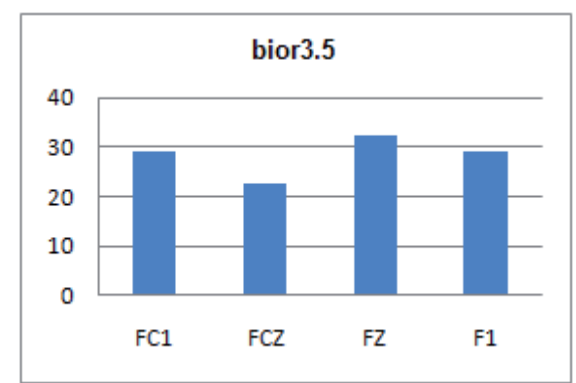

Fig. 32. Errors bior3.5

The error is still more than the $80 \%$, but the success is higher than rbio family. 


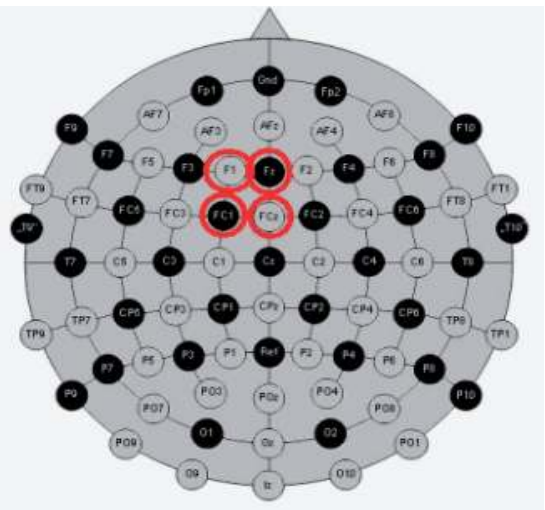

Fig. 33. Electrodes localization for bior3.5

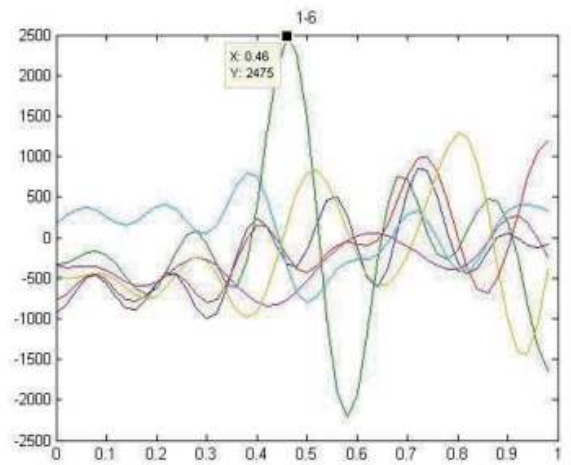

Fig. 34. Letter N, columns, FCZ

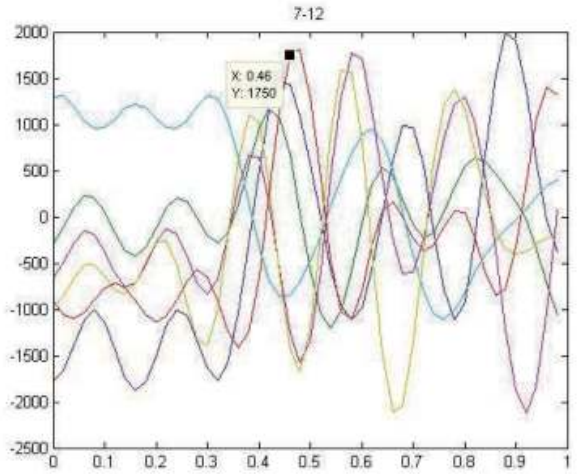

Fig. 35. Letter N, rows, FCZ 
bior3.7

\begin{tabular}{|l|l|l|l|l|}
\hline Word & FCZ & AFZ & FZ & F2 \\
\hline FOOD & FCCC- & ECCC- & FCCC- & FCCC- \\
\hline MOOT & MQOT- & MQOT- & MQOT- & MQOT- \\
\hline HAM & HAM-- & HAM-- & HAM- & HAM- \\
\hline PIE & PIE- & PIE- & FIE- & P1E- \\
\hline CAKE & CAKE- & CAKE- & CAKE- & CAKE- \\
\hline TUNA & TUNA- & TUNA- & TUNA- & TUNA- \\
\hline ZYGOT & ZSGOT & ZYGOX & ZYGOX & ZYGOX \\
\hline 4567 & $4 Y 67-$ & $4567-$ & 4Y67- & 4Y67- \\
\hline Success & $80.65 \%$ & $80.65 \%$ & $80.65 \%$ & $80.65 \%$ \\
\hline
\end{tabular}

Table 8. Predicted letters for bior3.7

Average of the 4 channels: $80.65 \%$

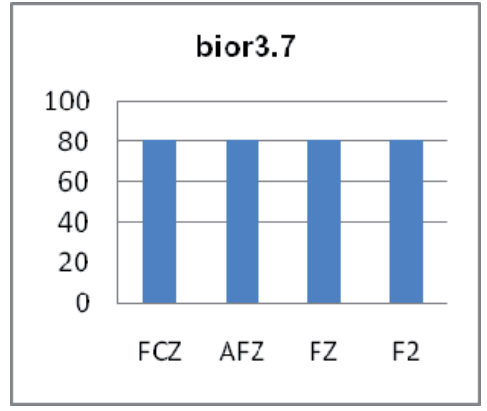

Fig. 36. Channel comparison for bior3.7

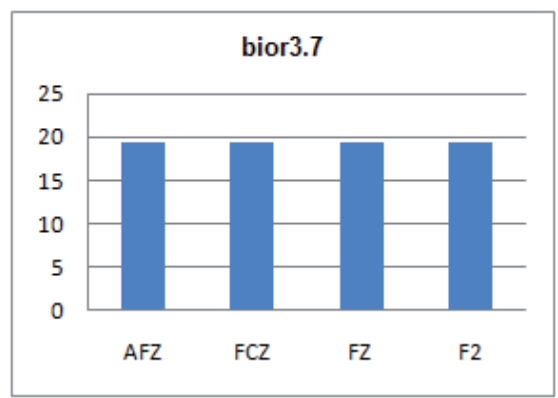

Fig. 37. Errors bior3.7

The four channels have an error less than the $80 \%$, so the result is acceptable. 


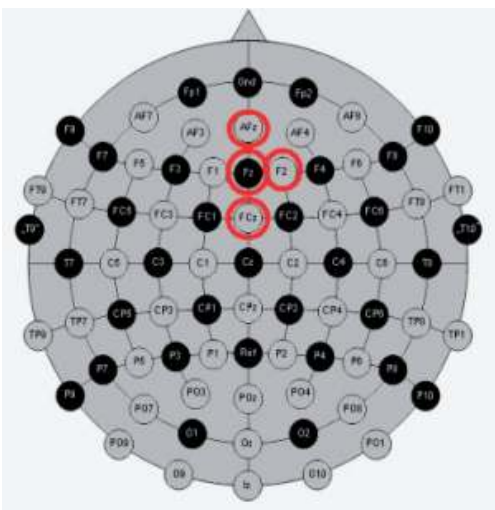

Fig. 38. Electrodes localization for bior3.7

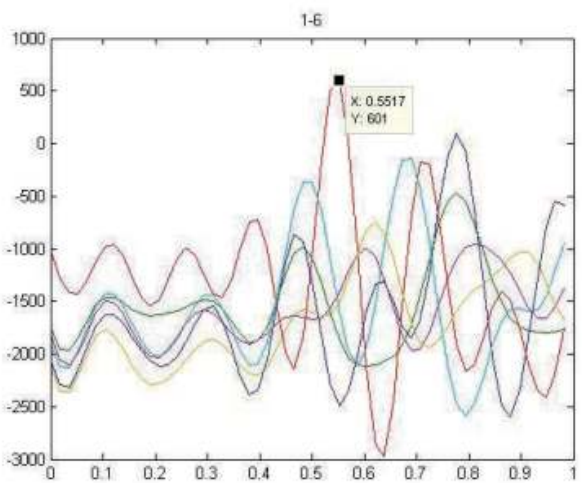

Fig. 39. Letter C, columns, FC2

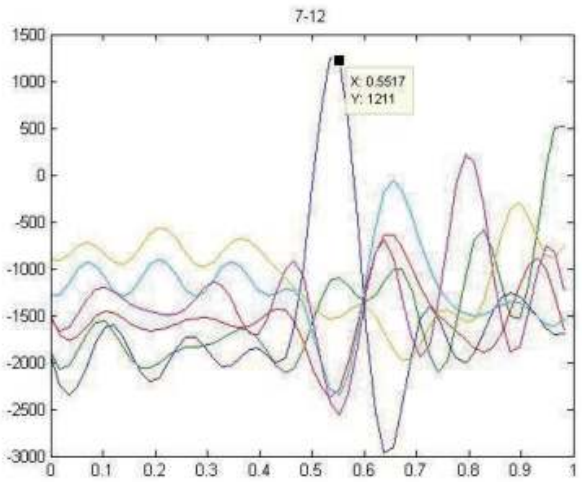

Fig. 40. Letter C, rows, FC2 
bior3.9

\begin{tabular}{|l|l|l|l|l|}
\hline Word & FC1 & FCZ & FZ & F2 \\
\hline FOOD & FCCC & ECCC- & ECCC- & ECCC- \\
\hline MOOT & MQOT- & MQOT- & MQOT- & MQOT- \\
\hline HAM & HAM-- & HAM- & HAM- & HAM- \\
\hline PIE & PIE- & P1E- & H1E- & HIE- \\
\hline CAKE & CAKE- & CAKE- & CAKE- & CAKE- \\
\hline TUNA & TUNA- & TUNA- & TUNA- & TUNA- \\
\hline ZYGOT & ZYGOT & ZYGOX & ZYGOX & ZYGOX \\
\hline 4567 & $4567-$ & $4567-$ & $4557-$ & 4 Y67- \\
\hline Success & $87.1 \%$ & $80.65 \%$ & $\mathbf{7 7 . 4 2 \%}$ & $\mathbf{7 7 . 4 2} \%$ \\
\hline
\end{tabular}

Table 9. Predicted letters for bior3.9

Average of the 4 channels: $80.65 \%$

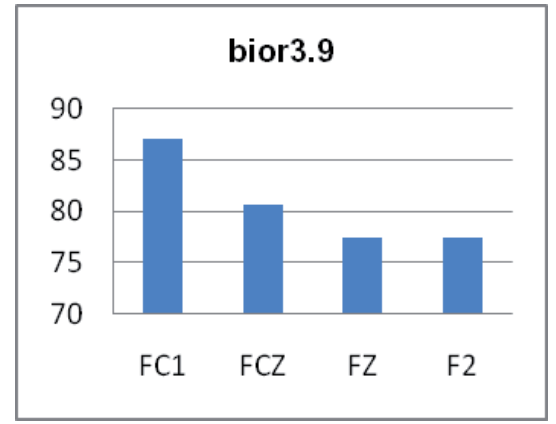

Fig. 41. Channel comparison for bior3.9

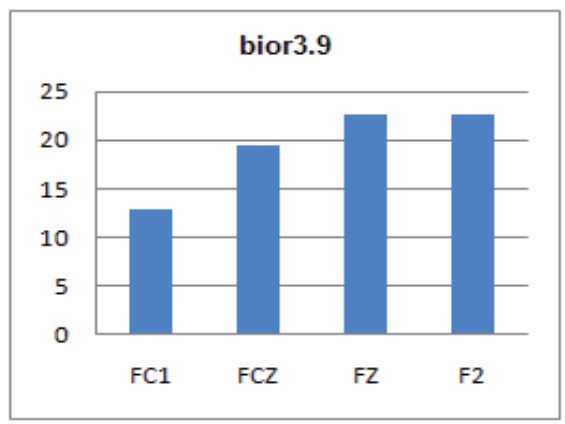

Fig. 42. Errors bior3.9

In this case, only two channels are over the $80 \%$ of success, but it can be observed that the channel FC1 has an error less than the $15 \%$. 


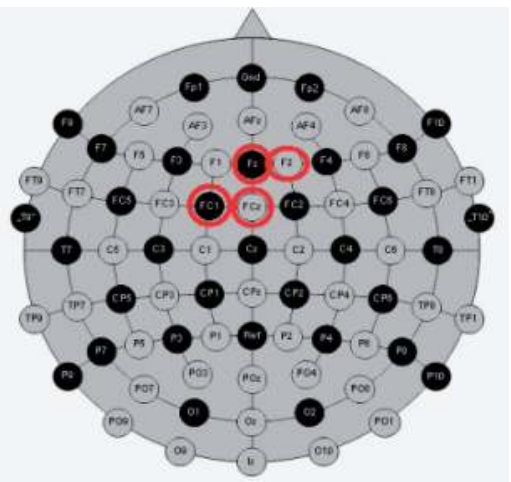

Fig. 43. Electrodes localization for bior3.9

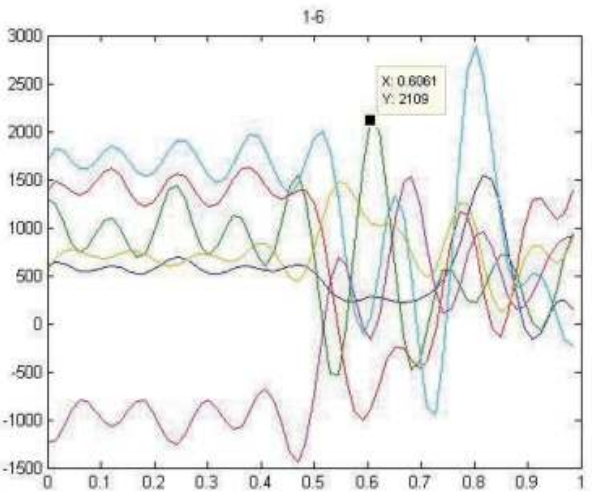

Fig. 44. Letter Z, columns, FC1

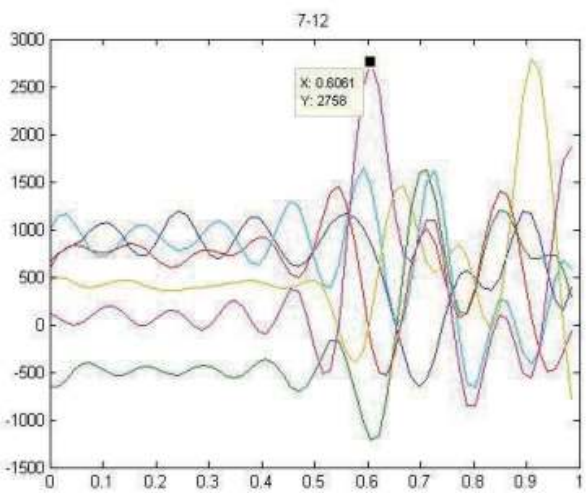

Fig. 45. Letter Z, rows, FC1 
bior3.3

\begin{tabular}{|l|l|l|l|l|}
\hline Word & FCZ & FC2 & FZ & F2 \\
\hline FOOD & ECCC- & FCCC- & ECCC- & FCCC- \\
\hline MOOT & MOOT- & GOOT- & GOOT- & GQOT- \\
\hline HAM & AAM-- & AAM-- & AAM- & AAM- \\
\hline PIE & PIE- & PIE- & PIE- & PIE- \\
\hline CAKE & CAKE- & CFKE- & CAKE- & CAKE- \\
\hline TUNA & TOBA- & TOBA- & TCBA- & TCBA- \\
\hline ZY GOT & ZSAON & ZSAOR & ZSA ON & Z5AOR \\
\hline 4567 & $4 Y 67-$ & $4 Y 67-$ & XY57- & XY57- \\
\hline Success & $64.52 \%$ & $61.29 \%$ & $54.84 \%$ & $54.84 \%$ \\
\hline
\end{tabular}

Table 10. Predicted letters for bior3.3

Average of the 4 channels: $58.87 \%$

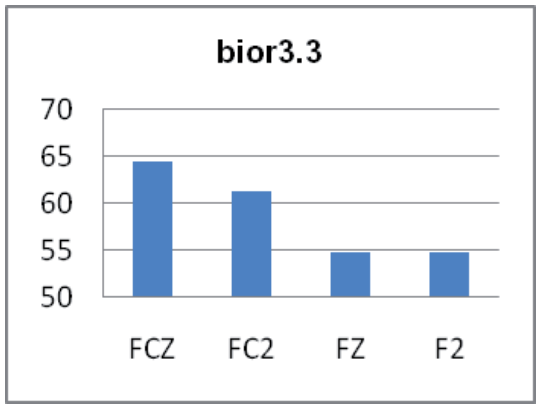

Fig. 46. Channel comparison for bior3.3

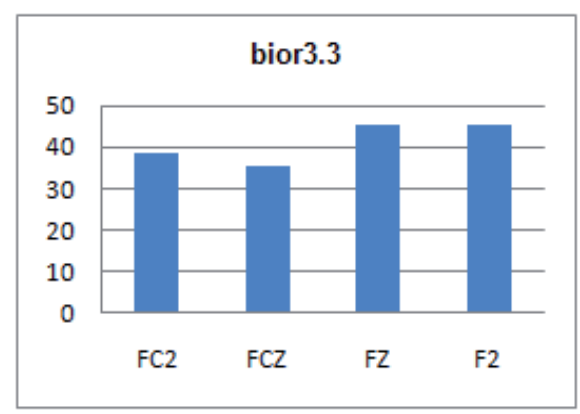

Fig. 47. Errors bior33

Within the family of the bior, the bior3.3 is the one which presents higher errors, exceeding all of them the $35 \%$. 


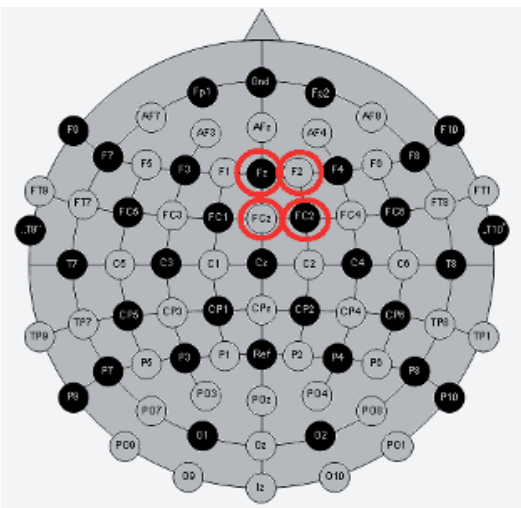

Fig. 48. Electrodes localization for bior3.3

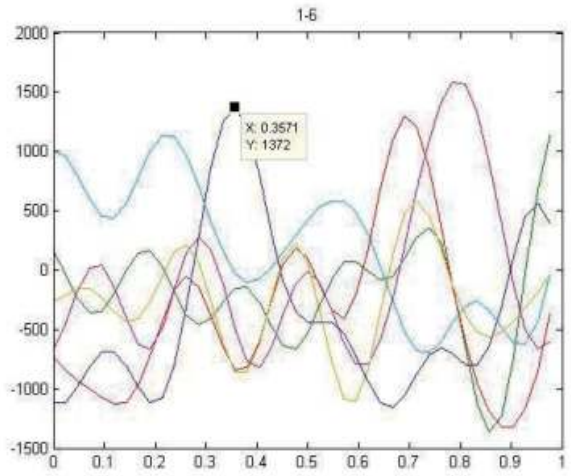

Fig. 49. Letter M, columns, FCZ

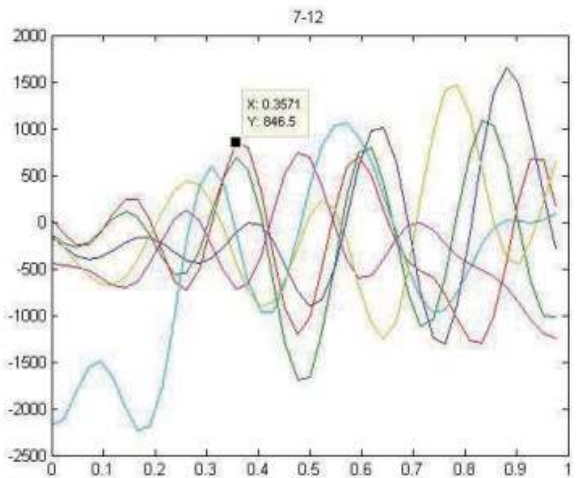

Fig. 50. Letter M, rows, FCZ 
DB9

\begin{tabular}{|l|l|l|l|l|}
\hline Word & FCl & FCZ & Cl & CZ \\
\hline FOOD & ECFC- & ECFD- & ECCD- & BCCD- \\
\hline MOOT & MQOW- & MQOW- & MQOW- & MQOW- \\
\hline HAM & 6AM- & HAM-- & HAM-- & HAM- \\
\hline PIE & PIB- & PIE- & PIE- & PIE-- \\
\hline CAKE & CAKE- & CAKE- & CAKE- & CAKE- \\
\hline TUNA & XUNA- & XUNA- & XUNA- & XUNA- \\
\hline ZYGOT & Z5GOX & $45 G O X$ & Z5GIX & Z5GOX \\
\hline 4567 & $4587-$ & $4567-$ & $4567-$ & $4567-$ \\
\hline Success & $61.3 \%$ & $\mathbf{7 0 . 9 7} \%$ & $\mathbf{7 0 . 9 7 \%}$ & $\mathbf{7 4 . 1 9} \%$ \\
\hline
\end{tabular}

Table 11. Predicted letters for DB9

Average of the 4 channels: $69.36 \%$

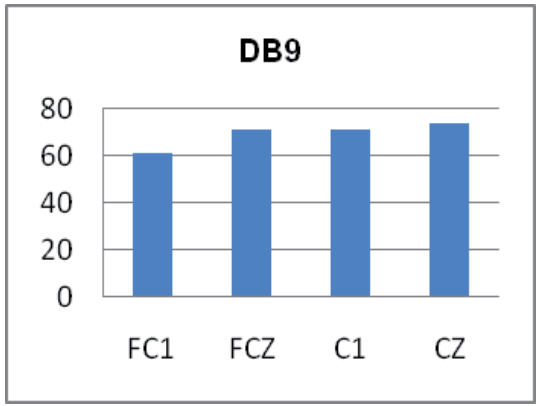

Fig. 51. Channel comparison for DB9

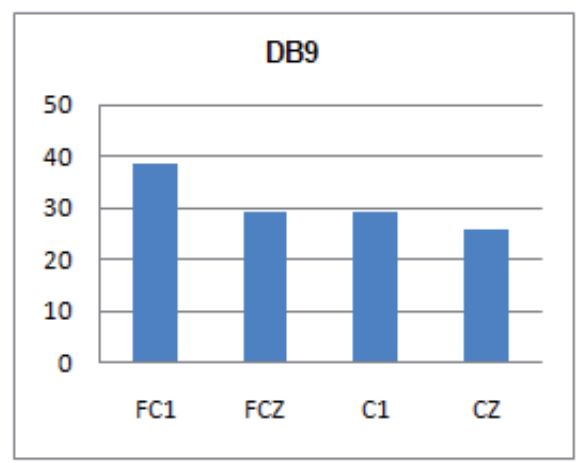

Fig. 52. Errors DB9

The success rate of the DB9 is higher than the rbio family, but it presents higher errors than the bior family (except for the bior3.3). 


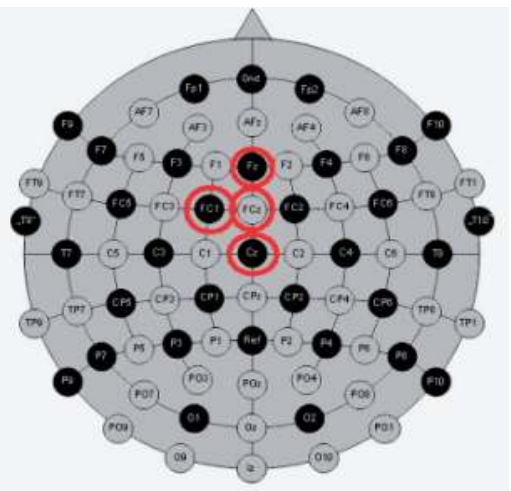

Fig. 53. Electrodes localization for DB9

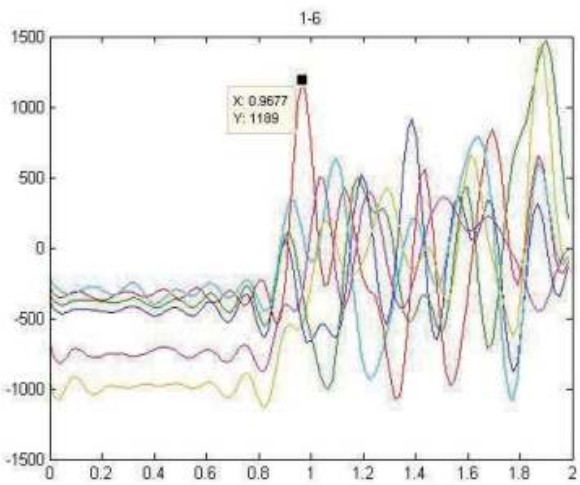

Fig. 54. Letter C, columns, CZ

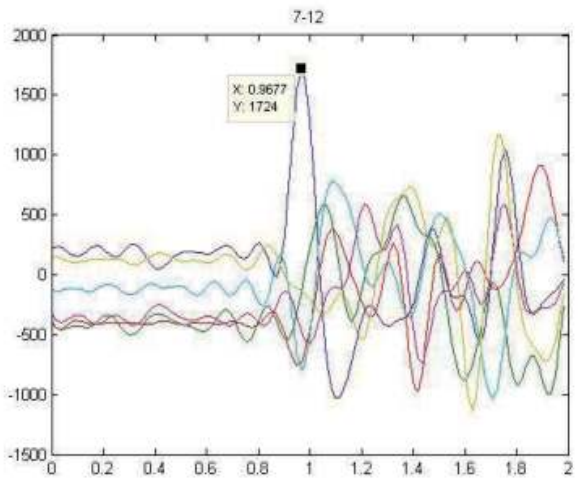

Fig. 55. Letter C, rows, $\mathrm{CZ}$ 
Following it can be observed the typical deviation of each wavelet. The deviation has been obtained using the corresponding average of each one:

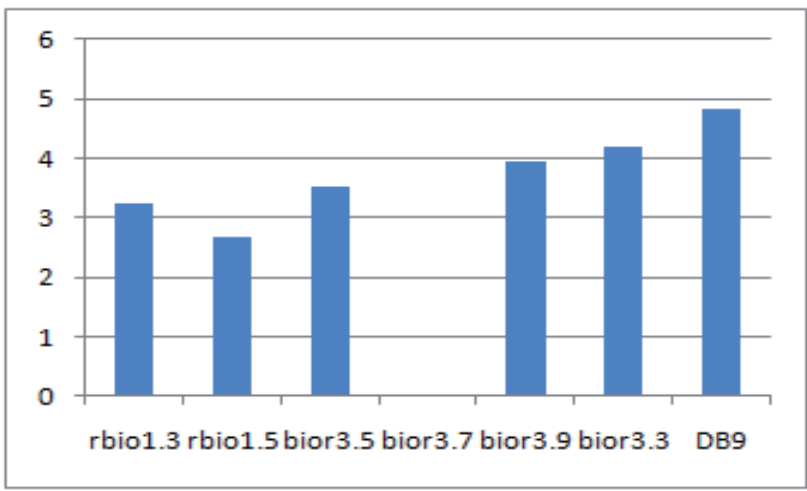

Fig. 56. Typical deviation from the average of each one

The value of the bior3.7 stands out from the rest because its four channels have the same value $(80.65 \%)$, so the deviation is zero.

The DB9 presents de highest typical deviation because it has a big difference between FC1 and $\mathrm{CZ}$.

We also present another graph with the typical deviation, but in this case, the deviation has been calculated respect to the average of the seven chosen wavelets $(71 \%)$ :

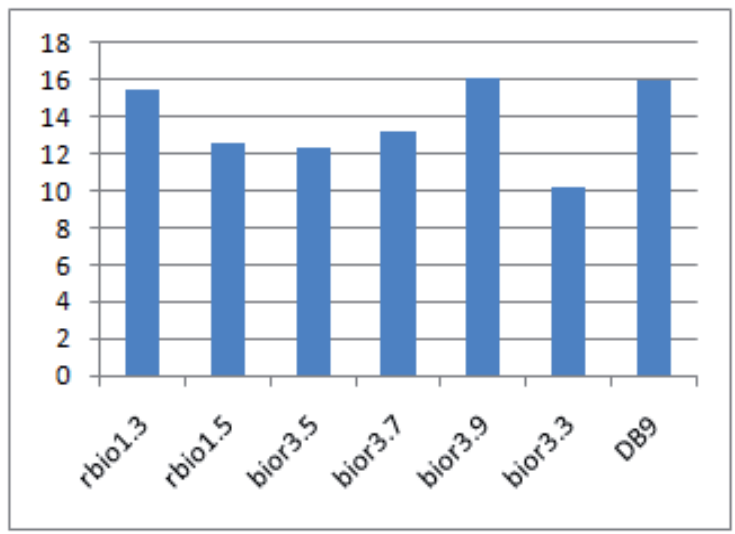

Fig. 57. Typical deviation from the average of the seven wavelets

This figure shows the average of the best four channels of each mother wavelet: 


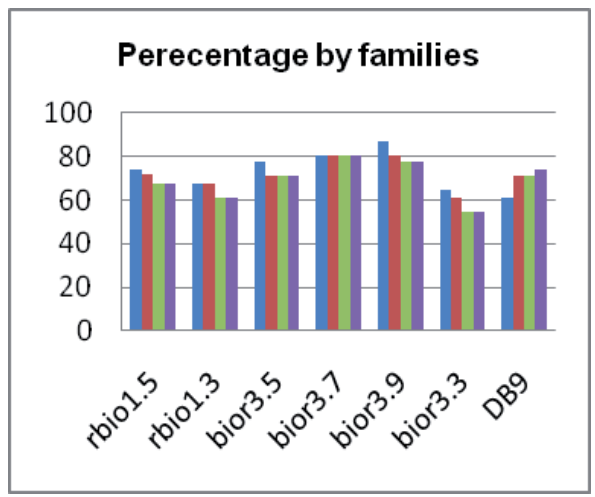

Fig. 58. Percentage of success by families

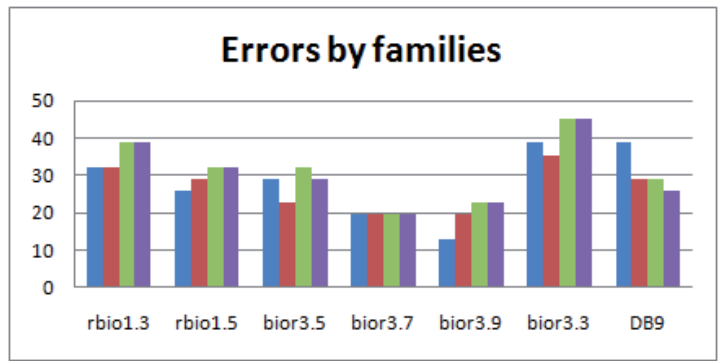

Fig. 59. Percentage of errors by families

As we can see, the best percentage corresponds to the channel FC1 with the wavelet bior3.9, but the wavelet with best average is the bior3.7, so this is the chosen one.

It only has been shown the best four channels for the bior3.7, but it also presents results that overcome the $65 \%$.

\begin{tabular}{|l|l|}
\hline FC1 & 77,41935484 \\
\hline FC2 & 74,19354839 \\
\hline C1 & 67,74193548 \\
\hline CZ & 70,96774194 \\
\hline AF3 & 67,74193548 \\
\hline F1 & 74,19354839 \\
\hline F4 & 70,96774194 \\
\hline
\end{tabular}

Table 12. Channels for the bior3.7

The electrodes are localized in the frontal lobe, which is the region that, among other functions, is responsible for the attention functions; and in the parietal lobe. 
The order of success of the seven used wavelets is the following (from the best to the worst):

\begin{tabular}{|r|l|r|}
\hline Order & Wavelet & Average(\%) \\
\hline 1 & bior3.7 & 80.65 \\
\hline 2 & bior3.9 & 80.65 \\
\hline 3 & bior3.5 & 72.58 \\
\hline 4 & rbio1.5 & 70.415 \\
\hline 5 & DB9 & 69.36 \\
\hline 6 & rbio1.3 & 64.52 \\
\hline 7 & bior3.3 & 58.87 \\
\hline
\end{tabular}

Table 13. Order of success

The worst results corresponds to rbio1.3 and bior3.3, which are the wavelets with the lower order of the filter. The lower the filter is, the more frequencies are allowed by it.

The following table shows the different selected channels and the time where the peak is detected:

\begin{tabular}{|l|l|l|}
\hline Wavelet & Channels & Time $(\mathrm{sc})$ \\
\hline bior3.7 & FCZ-AFZ-FZ-F2 & $\approx 0.55$ \\
\hline bior3.9 & FC1-FCZ-FZ-F2 & $\approx 0.6$ \\
\hline bior3.5 & FCZ-FC1-F1-FZ & $\approx 0.46$ \\
\hline rbio1.5 & FC1-FCZ-FZ-CZ & $\approx 0.41$ \\
\hline DB9 & FC1-FCZ-C1-CZ & $\approx 0.97$ \\
\hline rbio1.3 & FC1-FCZ-FZ-F2 & $\approx 0.32$ \\
\hline bior3.3 & FCZ-FC2-FZ-F2 & $\approx 0.37$ \\
\hline
\end{tabular}

Table 14. Channels and times

The difference of the time that the peak appears is due to the order of the filter: the higher the order is, the later the peak will appear.

This table contains the advantages and disadvantages comparing with each other:

\begin{tabular}{|c|l|l|}
\hline Wavelet & Advantages & Disadvantages \\
\hline bior3.7 & High Success & Peak appears late \\
\hline bior3.9 & High Success & Peak appears late \\
\hline bior3.5 & $\begin{array}{c}\text { Succes acceptable for } \mathrm{BCl} \\
\text { Peak appears before } 0.5 \text { seconds }\end{array}$ & Success less than the $80 \%$ \\
\hline rbio1.5 & $\begin{array}{c}\text { Succes acceptable for } \mathrm{BCl} \\
\text { Peak appears before } 0.5 \text { seconds }\end{array}$ & Success less than the $80 \%$ \\
\hline DB9 & Succes acceptable for $\mathrm{BCl}$ & Peak appears late \\
\hline rbio1.3 & Peak appears early & Low success \\
\hline bior3.3 & Peak appears early & Low success \\
\hline
\end{tabular}

Table 15. Advantages and disadvantages 
The ideal situation would be one wavelet with a high success and with the peak appearing as soon as it is possible.

This is difficult to obtain because to get precision, we need one mother wavelet with a high order, but this situation makes that the peak is delayed.

Although the chosen wavelet (bior3.7) shows the peak after 500 milliseconds, it does not mean that this delay represents any problem at the final application.

The first thing is because the P300 appears between 0.3 and 0.6 milliseconds since the stimulus is detected.

The second part is that, in order to ensure a good level decomposition, we have used samples until 2 seconds since the letter is illuminated. If the decomposition wasn't conditioned by the number of samples, the sample frequency could be lower.

The bior3.5, rbio1.5 and DB9 don't arrive at the established $80 \%$, but their average is superior than 65 , so the results are acceptable, although they are not enough in this application.

Following, it is presented the error of those mother wavelets that don't arrive at the objective, being the theoretical value the $80 \%$ :

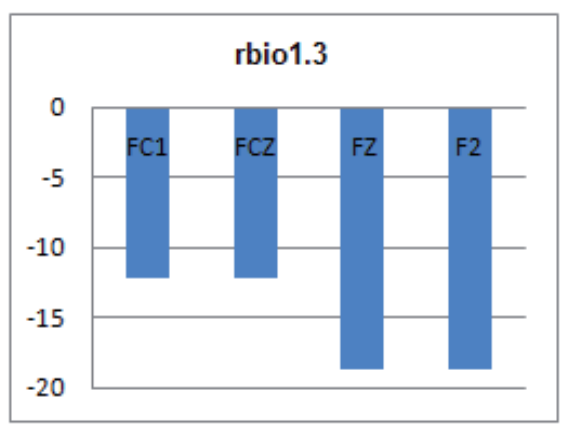

Fig. 60. Error rbio1.3 respect $80 \%$

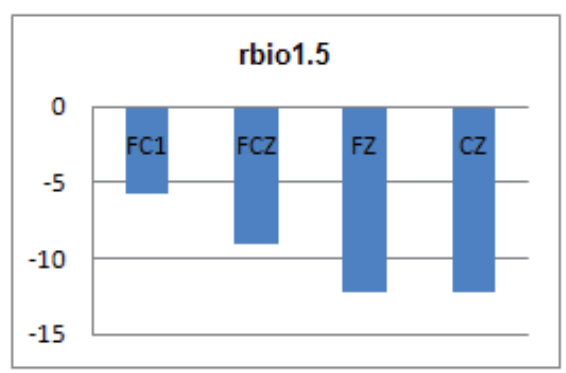

Fig. 61. Error rbio1.5 respect $80 \%$ 


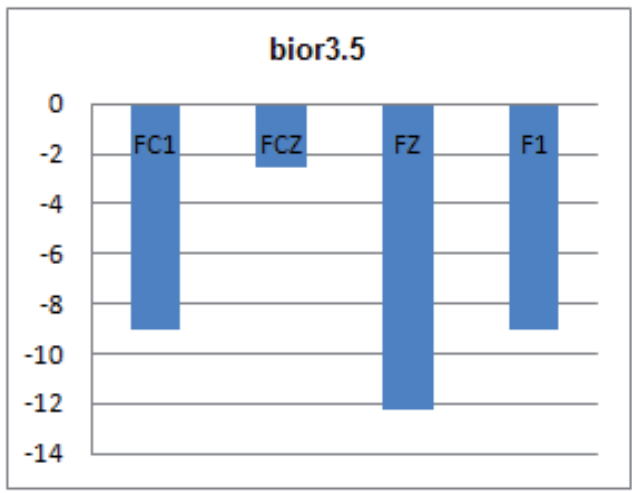

Fig. 62. Error bior3.5 respect $80 \%$

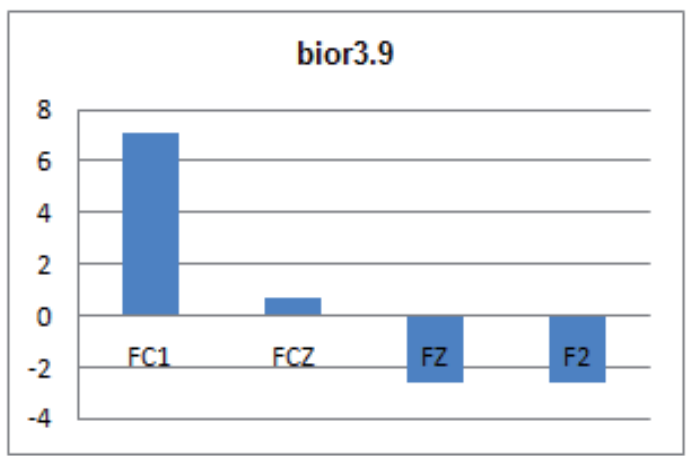

Fig. 63. Error bior3.9 respect $80 \%$

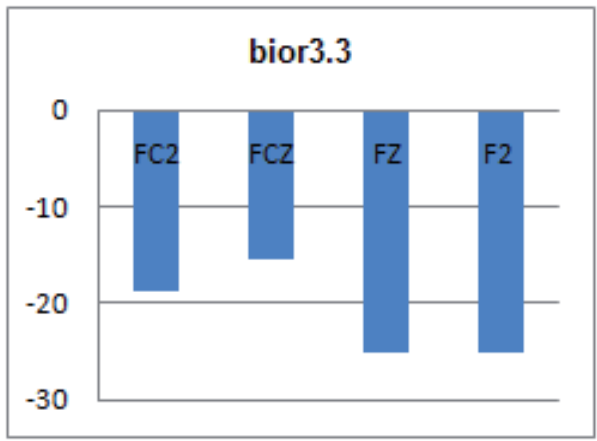

Fig. 64. Error bior3.3 respect $80 \%$ 


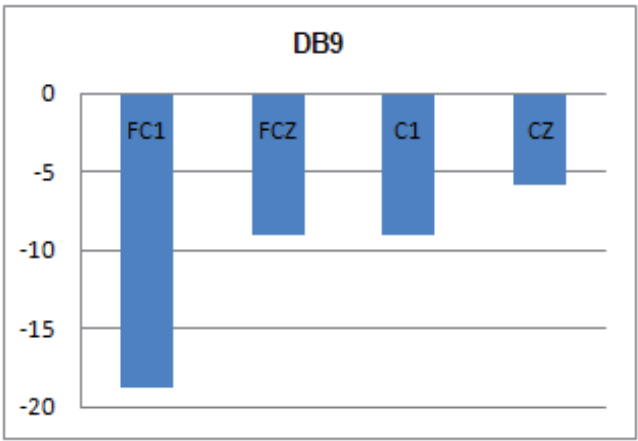

Fig. 65. Error DB9 respect $80 \%$

The error is negative to indicate that the success doesn't arrive at the established objective. It can be observed at bior3.9, where FC1 and FCZ overcome the $80 \%$ and the error (which is not an error in this case) is positive.

Bior3.3 is the one which is the farthest, with two channels with a distance higher than the $20 \%$.

On the contrary, the bior 3.9 practically arrives at the $80 \%$, because the error of FZ and F2 is less than a $3 \%$.

The following figures show the Wavelet Transform for the word HAT, with the wavelet bior3.7.

Letter H: column 2 and row 2:

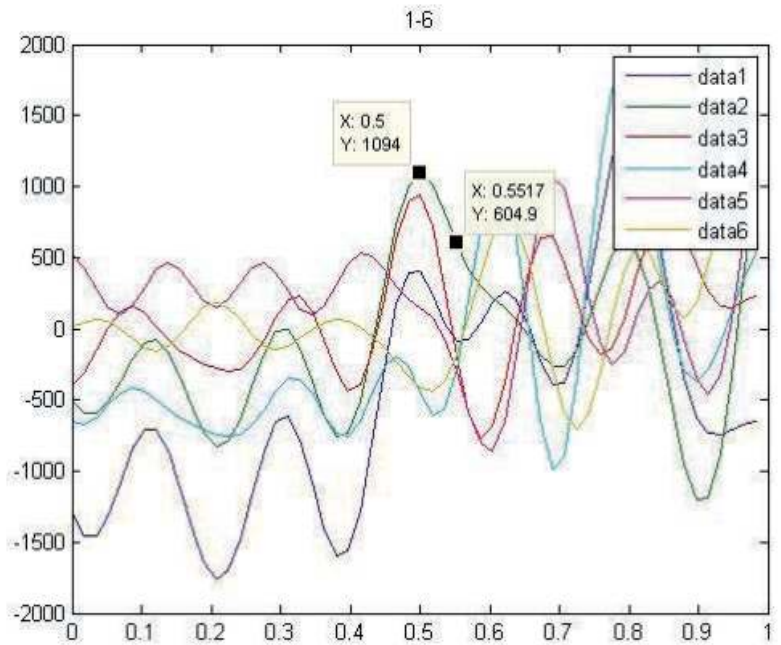

Fig. 66. Letter H, columns 


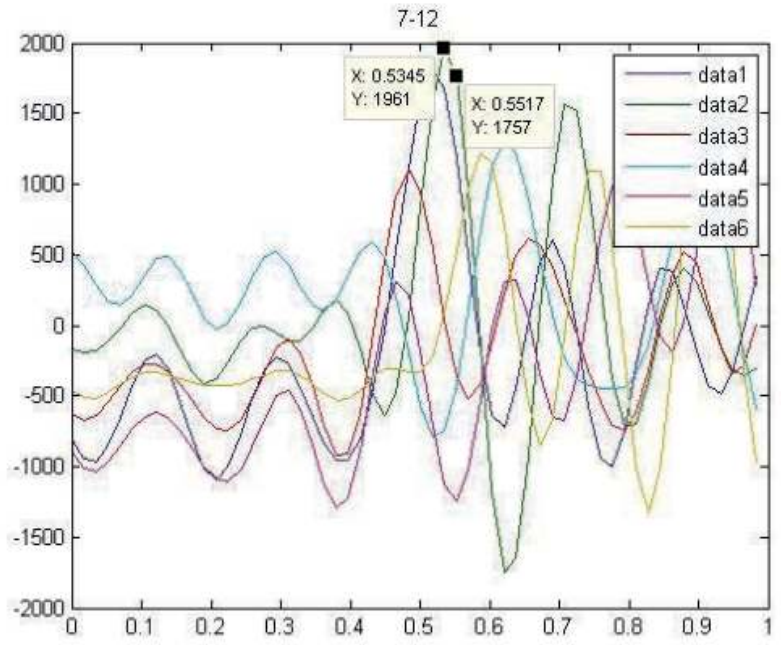

Fig. 67. Letter $\mathrm{H}$, rows

Letter A: column 1 and row 1 :

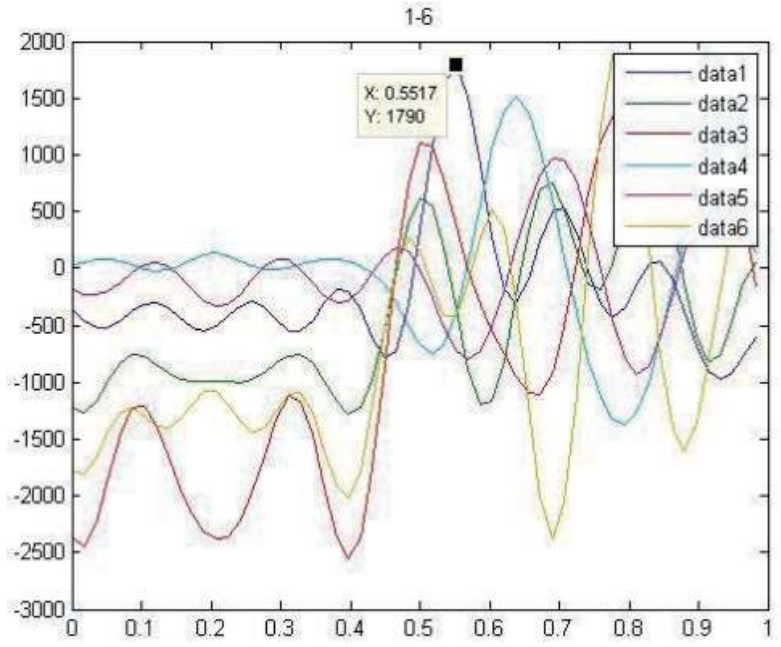

Fig. 68. Letter A, columns 


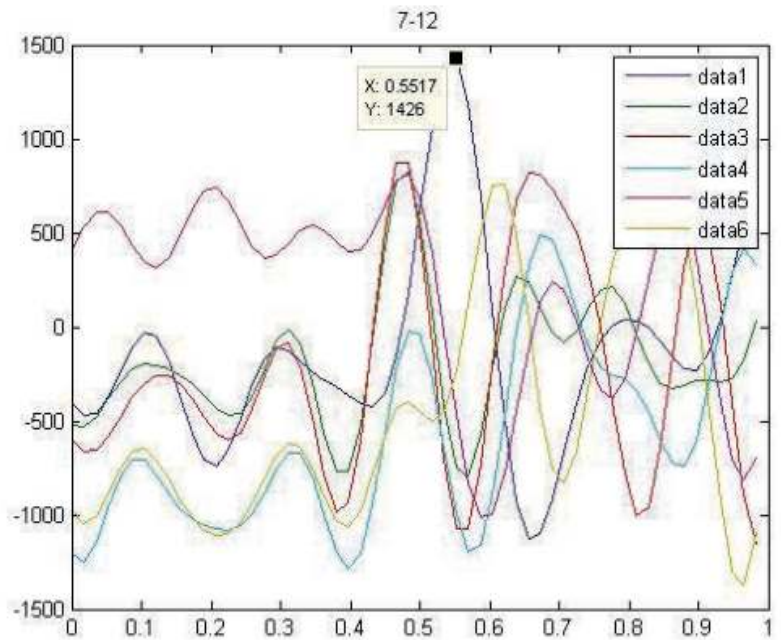

Fig. 69. Letter A, rows

Letter T: column 1, row 2

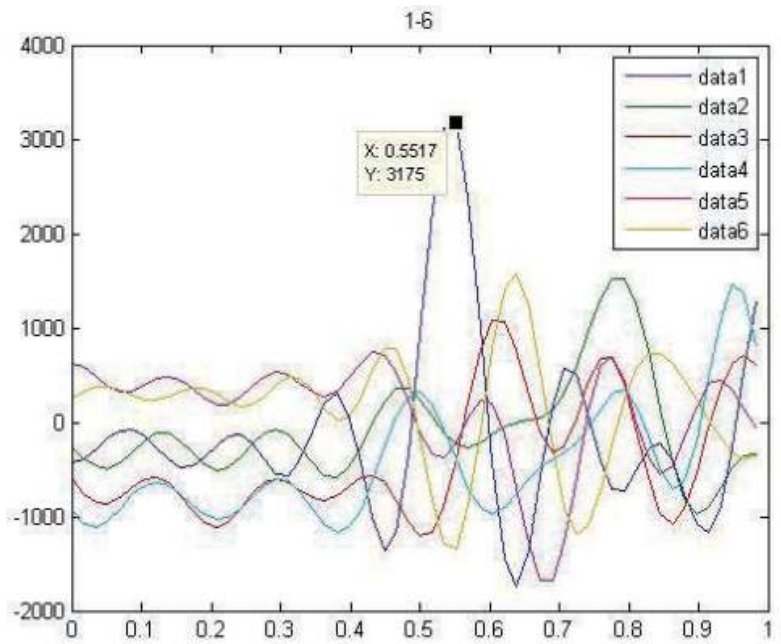

Fig. 70. Letter T, columns 


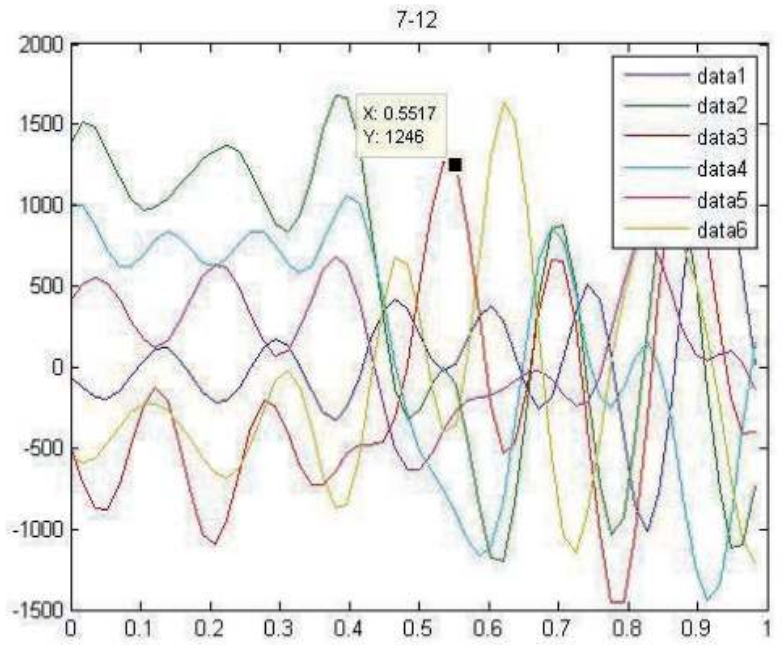

Fig. 71. Letter T, rows

\section{Discussion}

The performed algorithm is intended to be integrated in an application where the temporal answer must be the minimum possible. Although it's an initial study of the P300 after the Wavelet Transform, the method focus to the posterior real application, so, even existing methods and calculations that would improve the hit rate, they are not applied due to the time that it suppose.

It is considerate as valid those results with a hit rate higher than an $80 \%$.

It has made only comparisons between the different rows and columns to know which ones differ more than the rest in its behavior. It considers as target row and target column the two ones which show more difference respect to the rest.

It has been made entirely with the wavelets given by Matlab, being the bior3.7 the wavelet with best results.

Using other statistical methods after the transformation, and also with a quadratic B-Sprow, it can obtain higher results [19], but it supposes employ more time in calculations.

For the final application, it wouldn't need a previous stage of training to difference between targets and non targets, because there has not been used any classifier.

In this study it has been used the 64 channels to know in which ones of them exists higher difference between the P300b and the P300a, in order to chose the best four channels that will be used in the application. In many studies the occipital region shows higher hit rates [18], although it can also be appreciated some differences in the frontal part [20]. Nevertheless, in [4] they point that the P300 can appear in the parietal and temporal zone. 


\section{Future research}

There can differentiate three lines of actuation:

1. Improve the success of the algorithm in order to be more reliable without increasing the time due to the calculations that it supposes. This could be possible, among other things, by making our own wavelet, so that the noise that the used wavelets add to the signal could be minimized.

2. Use the algorithm in other applications where is necessary analyze signals in frequency bands, such as epilepsy problems.

3. Use other methods to work with EEG signals, such as Matching Pursuit.

\section{Acknowledgment}

Finally I would like to thank to those people who have collaborated in the elaboration of the study and the final application: Begoña García Zapirain, director of the Final Project where the study is integrated; Eneko Lopetegui, main creator of the application and is the one who proposed me using wavelets; John O'Toole, who gave me good advices at the time of working with wavelets; and at last, to the Arrieta sisters, who showed interest for the project since the first time.

Special mention should also go to the Education, University and Research Department from the Basque Government for their support of the project.

\section{References}

[1] Ibáñez J, Serrano J.I, del Castillo M.D, Barrios L, Gallego J.A, and Rocon E.(2011). An EEG-Based Design for the Online Detection of Movement Intention. LNCS 6691, p. 370 ff.

[2] Lopez-Gordo M.A, Ron-Angevin R, and PelayoValle F. (2011). Auditory Brain-Computer Interfaces for Complete Locked-In Patients. LNCS 6691, p. 378 ff.

[3] Mallat S. (2009). A Wavelet Tour of signal processing. Third edition: the Sparse Way. Burlington.

[4] Cardinali D. P. (2007). Neurociencia aplicada: sus fundamentos .Edit: Médica panamericana.

[5] Perez A, La Mura G, Piotrkowski R, Serrano E. (2002). Procesamiento no lineal con Wavelet para la eliminación del ruido en imágenes planares de medicina nuclear. Elsevier.

[6] Prochazka Al, and Kukal J. (2008). Wavelet Transform Use for Feature Extraction and EEG Signal Segments Classification. in 3rd International Symposium on Communications, Control and Signal Processing, 2008.

[7] Kitayama M, Otsubo H, Parvez S, Lodha A, Ying E, Parvez B, iIshii R, MizunoMatsumoto Y, Zoroofi R. A, Snead O.C. (2003). Wavelet analysis for neonatal electroencephalographic seizures. In Elseiver.

[8] Zarjam P. (2003). EEG Data acquisition and automatic seizure detection using wavelet transforms in the newborn EEG. Thesis

[9] Chazal P, Celler B. G. and Reilly R. B. (2000). Using Wavelet Coefficients for the Classification of the Electrocardiogram. In Proceedings of World Congress on Medical Physics and Biomedical Engineering, Chicago, July 2000. 
[10] Mahmoodabadi S.Z, Alirezaie J, Babyn P. (2007). Bio-signal Characteristics Detection Utilizing Frequency Ordered Wavelet Packets. In Proceedings of ISSPIT 2007.

[11] Noble E. (2010). Wavelet analysis of Malaria in pregnancy. In proceedings of MIUA 2010.

[12] Demiralp T, Ademoglu A, Schürrmann M, Basar-Eroglu C, Basar E. (1999). Detection of P300 Waves in Single Trials by the Wavelet Transform (WT). Brain Lang. 1999 Jan;66(1):108-28.

[13] Demiralp T, Ademoglub A, Istefanopulosb Y, Basar-Eroglu C, Basar E. (2001). Wavelet analysis of oddball P300. In International Journal of Psychophysiology 39 (2001).

[14] Ramírez-Cortes J. M, Alarcon-Aquino V, Rosas-Cholula G, Gomez-Gil P, EscamillaAmbrosio J. (2010). P-300 Rhythm Detection Using ANFIS Algorithm and Wavelet Feature Extraction in EEG Signals. In Proceedings of the World Congress on Engineering and Computer Science 2010.

[15] Sorensen T.L, Olsen U.L, Conradsen I, Henriksen J, Kjaer T.W, Thomsen C.E, Sorensen H.B.D. (2010). Automatic epileptic seizure onset detection using Matching Pursuit: A case study. In Engineering in Medicine and Biology Society (EMBC), 2010 Annual International Conference of the IEEE.

[16] Hsua WY, Lin CC, Ju MS, Suna YN. (2007). Wavelet-based fractal features with active segment selection: Application to single-trial EEG data. In Journal of Neuroscience Methods 163 (2007) 145-160.

[17] Costagliola S, Dal Seno B, Matteucci M. (2009). Recognition and Classification of P300s in EEG Signals by Means of Feature Extraction Using Wavelet Decomposition. In Proceedings of International Joint Conference on Neural Networks, Atlanta, Georgia, USA, June 14-19, 2009.

[18] Gareis I. E, Gentiletti G. G, Acevedo R, Rufiner L. (2009). Extracción de características en interfaces cerebro computadoras mediante transformada wavelet discreta: Resultados preliminares. Memorias del XVII Congreso Argentino de Bioingenieria (SABI 2009), Number 167, page 58-62.

[19] Z. Seyyedsalehi, A.M. Nasrabadi, V. Abootalebi “Committee Machines and Quadratic B-sprow Wavelet for the P300 Speller Paradigm "

[20] Rakotomamonjy A. (2008). Ensemble of SVMs for BCI P300 Speller. Biomedical Engineering Transactions. Volume: 55 Issue: 3 On page(s): 1147 - 1154.

[21] Markazi S.A, Stergioulas S, Ramchurn L.S, Bunce A. (2006). Wavelet Filtering of the P300 Component in Event-Related Potentials. Engineering in Medicine and Biology Society, 2006. EMBS '06. 28th Annual International Conference of the IEEE

[22] Rosas-Cholula G, Ramírez-Cortes J.M, Alarcón-Aquino V, Martinez-Carballido J, Gómez-Gil P. (2010). On Signal P-300 Detection for BCI Applications Based on Wavelet Analysis and ICA Preprocessing. 2010 IEEE Electronics, Robotics and Automotive Mechanics Conference.

[23] Barbosa D.J, Ramos J, Lima C. (2008). Detection of small bowel tumors in capsule endoscopy frames using texture analysis based on the discrete wavelet transform. Engineering in Medicine and Biology Society, 2008. EMBS 2008. 30th Annual International Conference of the IEEE.

[24] Zhen L, Chan A.K. (2001). An artificial intelligent algorithm for tumor detection in screening mammogram. Transactions on Medical Imaging, IEEE. Volume: 20 Issue:7 On page(s): $559-567$. 
[25] Polikar R, Keinert F, Greer M.H. (2001). Wavelet analysis of event related potentials for early diagnosis of Alzheimer's disease. In: A. Wavelets in Signal and Image Analysis, From Theory to Practice, Kluwer Academic Publishers, Boston, 2001.

[26] Ishita H, Sakai M, Watanabe J, Chen W, Wei D. (2007). Development of P300 Detection Algorithm for Brain Computer Interface in Single Trial. In Proceedings of 7th IEEE International Conference on Computer and Information Technology, 2007.

[27] Salvaris M, Sepulveda F. (2009). Wavelets and ensemble of FLDs for P300 classification. In Proceedings of 4th International IEEE/EMBS Conference on Neural Engineering 2009.

[28] Adeli H, Ghosh-Dastidar S, Dadmehr S. N. (2007). A Wavelet-Chaos Methodology for Analysis of EEGs and EEG Subbands to Detect Seizure and Epilepsy. In IEEE Transactions on Biomedical Engineering. Volume: 54 Issue: 2 On page(s): 205 - 211.

[29] Ting W, Guo-Zehng Y, Bang-Hua Y, Hong S. (2008). EEG feature extraction based on wavelet packet decomposition for brain computer interface. Measurement Volume 41, Issue 6, July 2008, Pages 618-625.

[30] AlMuhit A, Islam S. and Othman M. (2004). VLSI Implementation of Discrete Wavelet Transform (DWT) for Image Compression. 2nd International Conference on Autonomous Robots and Agents December 13-15, 2004 Palmerston North, New Zealand.

[31] Secker, A;Taubman, D. (2001). Motion-compensated highly scalable video compression using an adaptive 3D wavelet transform based on lifting. Proceedings of ICIP 2001. Greece.

[32] Easwaramoorthy, D; Uthayakumar, R. (2010). Analysis of biomedical EEG signals using Wavelet Transforms and Multifractal Analysis. Proceedings of IEEE International Conference on Communication Control and Computing Technologies (ICCCCT), 2010. Ramanathapuram.

[33] Ayhan, T, Seker, S. (2011). Detemination of decision moments in EEG signals using DWT. Proceedings of International Symposium on Innovations in Intelligent Systems and Applications (INISTA). Istanbul.

[34] Shaker Maan M. (2005). EEG Waves Classifier using Wavelet Transform and Fourier Transform. International Journal of Biological and Life Sciences 1:2 2005.

[35] Cvetkovic, D, Übeyli E.D, Cosic I. (2008). Wavelet transform feature extraction from human PPG, ECG, and EEG signal responses to ELF PEMF exposures: A pilot study. Journal Digital Signal Processing, Volume 18 Issue 5, September, 2008. 
(C) 2012 The Author(s). Licensee IntechOpen. This is an open access article distributed under the terms of the Creative Commons Attribution 3.0 License, which permits unrestricted use, distribution, and reproduction in any medium, provided the original work is properly cited. 